Florida International University

FIU Digital Commons

FIU Electronic Theses and Dissertations

University Graduate School

$11-21-1997$

\title{
The relationship between participation in unethical behaviors during the nursing student experience and participation in unethical behaviors as a registered nurse
}

Lynne J. Bryant

Florida International University

DOI: $10.25148 /$ etd.FI14051864

Follow this and additional works at: https://digitalcommons.fiu.edu/etd

Part of the Community College Leadership Commons, and the Higher Education Commons

\section{Recommended Citation}

Bryant, Lynne J., "The relationship between participation in unethical behaviors during the nursing student experience and participation in unethical behaviors as a registered nurse" (1997). FIU Electronic Theses and Dissertations. 1879.

https://digitalcommons.fiu.edu/etd/1879 
FLORIDA INTERNATIONAL UNIVERSITY

Miami, Florida

THE RELATIONSHIP BETWEEN PARTICIPATION IN UNETHICAL BEHAVIORS DURING THE NURSING STUDENT EXPERIENCE AND

PARTICIPATION IN UNETHICAL BEHAVIORS AS A REGISTERED NURSE

A dissertation submitted in partial satisfaction of the requirements for the degree DOCTOR OF EDUCATION IN COMMUNITY COLLEGE TEACHING by

Lynne J. Bryant 
To: Dean I. Ira Goldenberg

College of Education

This dissertation, written by Lynne J. Bryant, and entitled The Relationship Between Participation in Unethical Behaviors during the Nursing Student experience and Participation in Unethical Behaviors as a Registered Nurse, having been approved in respect to style and intellectual content, is referred to you for judgment.

We have read this dissertation and recommend that it be approved.

Kathleen Blais

Paulette Johns6n

Janice R. Sandiford, Maffor Professor

Date of Defense: November 21, 1997

This dissertation of Lynne $\mathrm{J}$. Bryant is approved.

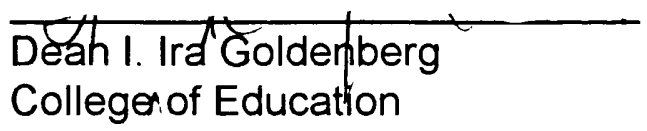

Dr. Richard L. Campbell

Dean of Graduate Studies

Florida International University, 1997 
() COPYRIGHT 1997 by Lynne J. Bryant

All rights reserved 
I dedicate this dissertation to my loving husband Gregg. His love and understanding was a tremendous support to me during this endeavor. 


\section{ACKNOWLEDGMENTS}

I wish to thank the members of my committee for their encouragement during this dissertation. They each contributed to this work in their own unique ways. Dr. Sandiford expertly guided me through the process. Dr. Blais helped me with the nursing educational aspects of the study. Dr. Johnson assisted me with the statistical analysis. The late Dr. Gay helped me with the design of the study.

I also wish to thank Dr. Diane Whitehead for her encouragement and assistance throughout my doctoral studies. 


\section{ABSTRACT OF THE DISSERTATION}

THE RELATIONSHIP BETWEEN PARTICIPATION IN UNETHICAL

BEHAVIORS DURING THE NURSING STUDENT EXPERIENCE AND

PARTICIPATION IN UNETHICAL BEHAVIORS AS A REGISTERED NURSE

by

Lynne J. Bryant

Florida International University, 1997

Professor Janice Sandiford, Major Professor

The effect of unethical behaviors in health care settings is an important issue in the safe care of clients and has been a concern of the nursing profession for some time. The purpose of this study was to examine the relationship between use of unethical behaviors in the nursing student experience and the use of unethical behaviors in the workplace as a registered nurse. In addition, the relationship between the severity of unethical behaviors utilized in the classroom, clinical setting and those in the workplace was examined. To insure greater honesty in self-report, only a limited umber of demographic variables were requested from participants.

During the summer of 1997, a 56 item questionnaire was distributed to registered nurses enrolled in either undergraduate or graduate courses in a public or private institution. The participants were asked to self-report their own 
use of unethical behaviors as well as their peers use of unethical behaviors. In order to assign a severity score for each item, nursing school faculty were asked to rate severity of unethical behaviors which could be used during the nursing student experience and nursing administrators were asked to rate unethical behaviors which could be used in the workplace.

A significant positive relationship was found between individuals' use of unethical behaviors during nursing school and those used in the workplace $\underline{r}=.630$. A significant positive relationship was found between the severity of unethical behaviors used in the nursing student experience and the severity of unethical behaviors used in the workplace $\underline{r}=.637$. No relationship was found between years of practice, type of initial nursing education and whether or not the participant was raised inside or outside the United States and the use of unethical behaviors. 
I. INTRODUCTION

Significance of the Problem …….................................................. 5

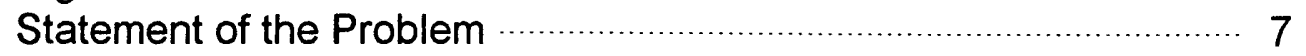

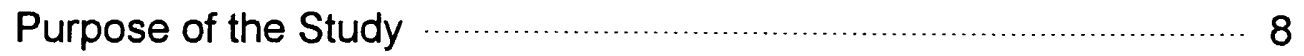

Hypotheses …..................................................................... 9

Research Questions ……......................................................... 8

Significance of the Study …...................................................... 10

Limitations of the Study ……....................................................... 10

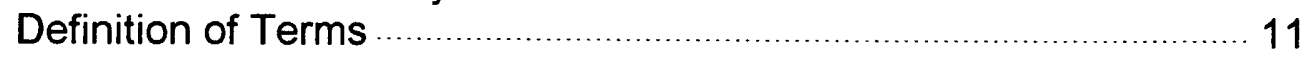

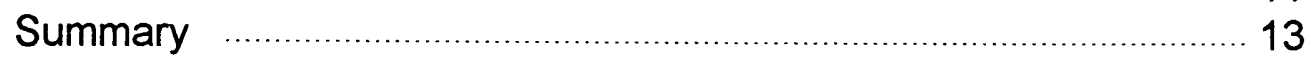

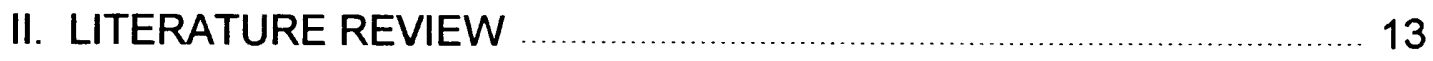

Student and Faculty Perceptions of Cheating .................................. 13

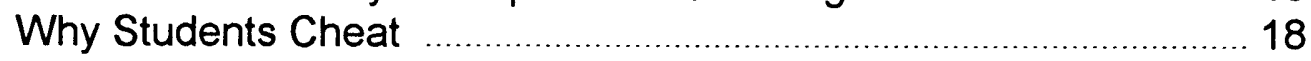

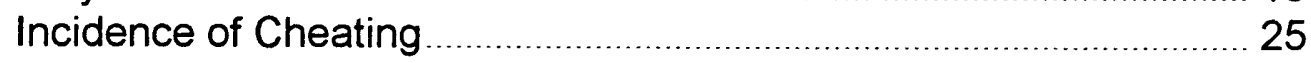

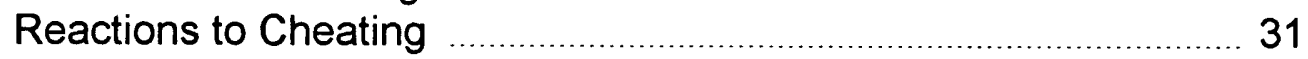

Prevention of Cheating …............................................................ 36

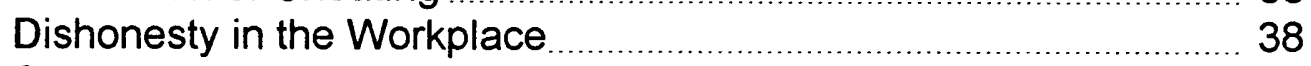

Summary

III. METHODOLOGY

Sample

Subjects

Instrument

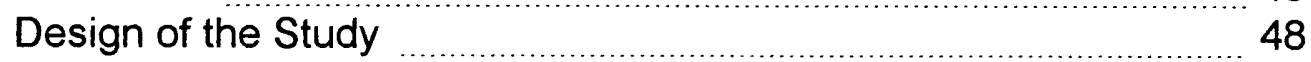

Procedure $\quad 48$

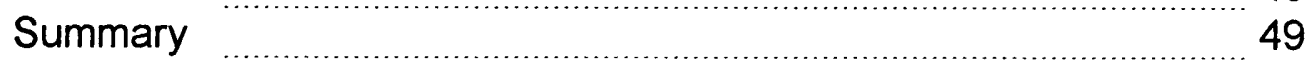

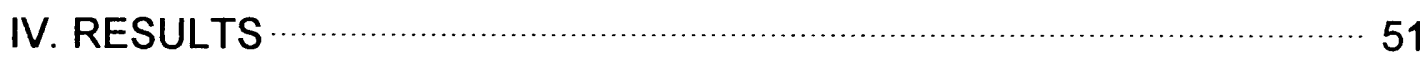

Analysis of Demographic Data …........................................... 51

Frequency of Participation in Unethical Behaviors …….................. 56

Relationship of Use of Unethical Behaviors ……...........................67

Severity of Unethical Behaviors Utilized ……................................... 70

Years of Practice and Use of Unethical Behaviors ……......................74

Type of Initial Education and Use of Unethical Behaviors …......... 76

Participation in Unethical Behaviors and Being Raised Inside or Outside the US ................................................................... 76

Frequency of Use of Unethical Behaviors by Peers ……….......... 78

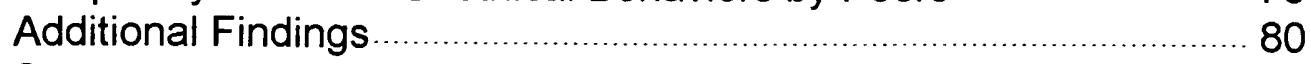

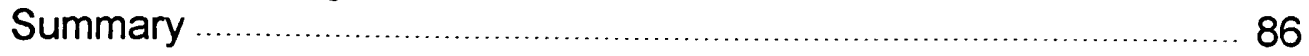




\section{TABLE OF CONTENTS}

(continued)

CHAPTER

PAGE

V. DISCUSSION

89

Discussion of Results

Conclusions

Recommendations

96

Implications for Research

98

List of References 101

Appendixes 


\section{LIST OF TABLES}

Table

PAGE

Table 1: Demographic Profile of Participants 53

Table 2: Demographic Profile of Participants by Current Enrollment

Table 3: Frequency of Use of Unethical Behaviors in the Classroom and Clinical Setting 58

Table 4: Frequency of Use of Unethical Behaviors in the Overall Student Experience and in the Workplace

Table 5: Frequencies and Severity Ratings for Self Report of Unethical Behavior Inventory

Table 6: Means, Standard Deviations and Correlation Between

Percent Use of Unethical Behaviors in the Workplace and Overall Student Experience, Classroom Setting and Clinical Setting

Table 7: Means, Standard Deviations and Correlation Coefficients Between Weighted Scores for Unethical Behaviors in the Workplace, Overall Student Experience, Classroom Setting, and Clinical Setting

Table 8: Correlation of Years of Practice with Percent Use of Unethical Behaviors in Overall Student Experience, Classroom Setting, Clinical Setting and Workplace

Table 9: Means, Standard Deviations for Percent Use of Behaviors by Type of Initial Nursing Education

Table 10: Means, Standard Deviations and $\underline{t}$ tests for Percent User of Unethical Behaviors in Four Settings by Whether Participants Were Raised Inside or Outside the United States

Table 11: Frequency of Participation in Unethical Behaviors in the Workplace as Reported for Themselves and for Peers

Table 12: Means and Standard Deviations of Use of Unethical Behaviors by Type of Current Enrollment 


\section{LIST OF TABLES}

Table 13: Differences in Percent Use of Unethical Behaviors in Student Clinical Setting and the Workplace for Matched Items 85 


\section{Chapter 1}

Introduction

One of the most important aspects of the nurse client relationship is the element of trust. Clients must have confidence that the nurse is administering the correct medications, giving and recording appropriate care without error, and maintaining confidentiality. Clients expect the nurse to be honest. In today's health care setting, the nurse caring for the client may be the same one who cheated on a test or fabricated home visits while a nursing student. This raises the question, does the nurse who participates in unethical behaviors as a student continue with these same practices in the workplace? The effect of these unethical behaviors is of importance to the issue of safe client care. The student who cheats on tests in order to graduate from nursing school may have an inadequate knowledge base. The effect of this lack of knowledge can have a detrimental effect on client care. The nurse may make an error because of inadequate knowledge of a client condition. A gap in the nurse's knowledge could also lead to that nurse participating in unethical practice behaviors such as performing procedures without adequate knowledge of them or covering up medication errors. These actions place clients' health in jeopardy.

\section{Background}

The American Association of Colleges of Nursing (1986) identified seven values that the professional nurse should possess. Three of these values, justice, human dignity, and truth, are directly related to the issue of honesty in 
nursing. Taylor, Lillis and LeMone (1997) elaborate on how these values are applied in nursing practice. The nurse who upholds human dignity for his/her client is the same one who maintains confidentiality. The nurse who upholds justice in nursing practice is the same one who reports unethical and illegal behaviors to the appropriate personnel. The nurse who is truthful records client data accurately. These values are usually addressed in a basic nursing course and become threads throughout the entire nursing curriculum. In addition, the American Nurses' Association has developed Standards of Clinical Nursing Practice (1991). Basic to these standards are ethical values, evaluating the nurse's own practice, and maintaining quality care. These standards are also part of most introductory nursing texts and are also included throughout the nursing student's course of study. Breaches of these precepts can lower the standard of nursing practice and the quality of client care. In addition, the integrity of the academic community may be harmed (Jeffreys \& Stier, 1995).

Television medical dramas are including the integrity of the nurse in their scripts. In a 1997 episode of ER, one of the nurses made an error that contributed to the death of a client. The two doctors working with the nurse told her they would look the other way if she didn't report this error because they felt it wasn't really her fault. The nurse in question did demonstrate professional practice and did report the error.

The Florida Nurse Practice Act, which governs the practice of nursing, also reflects values of truth, human dignity and justice. These values have now 
become regulations, which when violated can subject the nurse to disciplinary action. The Board of Nursing (1994) describes what is considered professional misconduct. Included in this description are the following: " inaccurate recording, falsifying or altering of client records", "administering medications or treatments in negligent manner", "misappropriating supplies, equipment or drugs", and "violating the confidentiality of information or knowledge concerning a client" (p. 54). Newsletters published by the Board of Nursing lists the names of violators of the rules and regulations. This list does not specify what the violation occurred, but does describe the disciplinary actions taken in response to a violation. During a ten month period, there were approximately 235 nurses who appeared before the Board of Nursing because of violations of the rules of nursing (Board of Nursing, 1997). This number represents a very small percentage of the nurses in Florida who have active licenses, but there may be many violations of the rules which go unreported.

In examining this issue, the concept of cheating among college students must be explored. Cheating by college students has been reported for decades. The rise in the incidence of cheating is alarming. Baird (1980) reviewed the frequency of college cheating from the 1950s until his study and reported a steady rise in rate of occurrence of cheating. In 1980, Baird surveyed 200 students and found that $75 \%$ of those students indicated that they cheated while in college. Sims (1993) reports that $91 \%$ of students who were surveyed reported cheating as undergraduate students. Students in helping professions 
are also involved in cheating. Sierles, Hendrickx, and Circle (1980) reported that the incidence of cheating was $87.6 \%$ in premedical students and $58.2 \%$ of medical students admit they cheated. Hilbert (1985) surveyed 101 nursing student in order to determine the incidence of unethical behaviors in the classroom and clinical settings. Hilbert defined unethical behaviors as "a broad range of actions that may occur in the classroom and in the clinical settings and that are generally considered as being dishonest or fraudulent" (p.231). Senior nursing students were given a questionnaire and asked to indicate which behaviors they thought were unethical and which were not. In addition, they were asked to indicate how many times they utilized these behaviors during the academic year. Students generally agreed about what they considered to be unethical behaviors. The incidence of cheating in the classroom was relatively low. Over half of the students indicated they had engaged in some type of unethical behavior in the clinical setting, $59 \%$ admitted that they had taken hospital equipment, and $54 \%$ had discussed clients in public places. There was a significant relationship between students who participated in dishonest classroom behaviors and unethical behaviors in the clinical setting. In 1987 , Hilbert reported results from a survey completed in four different sites and involving 210 nursing students. The results of this study revealed an increase in incidence in several of the unethical behaviors. Again, a significant positive relationship was found to exist between unethical classroom and clinical behaviors. 


\section{Significance of the Problem}

Does the nurse who participates in cheating while in college also continue with similar behaviors while practicing nursing? A search of the nursing literature revealed no studies that examined this critical point. Sims (1993) studied the relationship between academic cheating and work-related dishonesty in business students. Students who participated in a wide variety of academic dishonesty behaviors also were involved in a wide variety of dishonest behaviors in the workplace. Todd-Mancillas (1987) writes "just as students cheat in school as a means of coping with academic pressure, communications professionals may cheat as means of coping with the stressful demands of the marketplace" (p. 4). He cited several instances of fraud that occurred in the workplace in the communications industry. The most notable example of fraud was Janet Cooke who was awarded a Pulitzer Prize for her story about a child heroin addict. It was later demonstrated that Ms Cooke fabricated the story. Hawley and Jeffers (1992) examined the issue of scientific misconduct. They concluded that the number of cases of misconduct is not known, and may appear to be prevalent because of media attention on certain cases.

In the health related fields, several studies have demonstrated that there was a positive correlation between unethical behaviors in the classroom and in the client care areas. One such study was completed by Sierles, Hendrickx, and Circle (1980). They reported a positive correlation between cheating in the medical school classroom and similar behavior in caring for clients as medical 
students. The two previously cited studies by Hilbert $(1985,1987)$ demonstrated a positive relationship between participation in cheating behaviors in the classroom and in the clinical setting. A study was located which examined one specific area of dishonest behaviors by nurses in the workplace. Hackel, Butt, and Banister (1996) asked 146 nurses to estimate the number of medication errors that they had made in a three month period. According to those estimates, between 146 and 292 errors were made. During that same time period only 46 errors were reported according to hospital policy. This study indicated that a minimum of two thirds of medication errors went unreported. The lack of reporting of errors is not just confined to the individual involved, but also can involve institutions. A headline in the Miami Herald read "Unreported medical errors "a time bomb'." (Rogers, 1997). These errors must be reported according to state law, but they are not, Rogers reports. The Florida state legislature is examining the issue, and considering increasing fines for those facilities who do not comply. Although errors do occur, the problem in these cases is that the ones committing the errors fail to take responsibility for them and report them. Nurses' unethical behaviors while providing care can endanger the health of the client. This may result in legal actions against the nurse and the employing institution, which in turn may increase the cost of care, and adversely affect the public's image of the professional nurse (Jeffreys \& Stier, 1991).

Statement of the Problem

Although the registered nurse is licensed by a state's board of nursing 
and employed by a health care agency, much of the practice of the registered nurse is autonomous. Nurses are entrusted to complete assignments given to them with minimal supervision. It is very difficult to track unethical behaviors in this type of setting. Report of any errors or incidents which occur is dependent upon the honesty of the nurse. Nurses may not report such errors because they fear disciplinary action (Hackel, Butt \& Banister, 1996).

In Florida, one nursing instructor may have as many as twelve students in the clinical area. It is virtually impossible for one instructor to know what all students are doing at any given moment. In some cases, the instructor may have one or more students who may be considered unsafe, or at the very least need almost constant supervision. Most of the instructor's time is spent correcting and documenting the problems of these few students, while the rest of the students give care to assigned clients fairly independently. The instructor must rely on the honesty of students to report about care they have given. The instructor may be able to evaluate that the care was done, but not how well the student completed the care, or if another student actually did the care for the client. In the classroom setting, students have developed surreptitious means by which to cheat. Students described some unique techniques by which they cheat. These techniques include making paper flowers, writing notes on the inside and pinning them on their clothing; hiding a calculator in their pants, writing notes and hiding them in their mouth in a plastic bag, and finally, having a system of hand and foot signals to communicate with peers (Davis, Grover, Becker, \& McGregor, 
1992). The incidence of unethical behaviors in the classroom, student clinical practice, or nursing practice is not really known except by self-report. The relationship between unethical behaviors in the classroom, in the clinical setting and in the workplace setting is not known. It is also not known whether there is a relationship between the severity of unethical behaviors in any of these three areas, classroom, clinical or workplace.

\section{Purpose of the Study}

The purpose of this study is to examine the relationship between an individuals' use of unethical behaviors in the classroom or clinical setting during their nursing student experience and their participation in unethical practices in the workplace as registered nurses.

\section{Hypotheses}

The following hypotheses were developed. First, it is hypothesized that the individual who participates in unethical behaviors in the classroom or clinical setting during their nursing student experience will engage in unethical behaviors in the workplace as a registered nurse. Secondly, it is hypothesized that there is a relationship between the severity of unethical behaviors utilized in the classroom or clinical setting and those in the workplace.

\section{Research Questions}

In addition to testing the hypotheses, the data will also be analyzed to answer the following questions: 
1. What is the overall frequency of participation in unethical behaviors in each of the three settings? (i.e. classroom, clinical, workplace)

2. Which unethical behaviors are utilized most frequently by the participants in the study?

3. What is the relationship between the number of years of practice in nursing and the frequency of participation in unethical behaviors in the workplace?

4. What is the relationship between the initial type of nursing education (diploma, ADN, BSN) and participation in unethical behaviors as a registered nurse?

5. What is the relationship between being raised inside or outside the United States and participation in unethical behaviors?

6. What is the frequency of participation in unethical behaviors by registered nurses as reported by their peers?

Significance of the Study

Much of the research in cheating was done prior to 1990 . Very few studies exist which are specific to the nursing population at large. Those which have been completed examine, cheating in nursing school or participation in unethical behaviors in the workplace.

No study has examined the relationship between participation in unethical behaviors as a nursing student and participation as a registered nurse. It is 
important to determine if there is a relationship so that a plan of action can be formulated. The potential for harm to clients makes it imperative that this issue be addressed by nursing faculty and nursing administrators in the workplace.

\section{Limitations of the Study}

One of the main limitations of this study was related to the fact that participants were asked to self-report unethical behaviors. Studies have shown that these types of behaviors tend to be underreported (Hilbert, 1985).

Participants were asked to report personal unethical or dishonest behaviors. If a participant was dishonest in general, that participant was less likely to answer honestly. The risk that these behaviors were not being reported truthfully is inherent in this study.

Another limitation of the study was that the surveys were done in an academic setting. Registered nurses who were not currently pursuing baccalaureate or master's degrees were not included in the study, and may differ from the population studied. It was believed that local hospitals would not allow collection of data about unethical behaviors at their facilities. Therefore students enrolled in the academic courses were chosen as subjects.

The results of the surveys were specific to the population at the two South Florida institutions used for the study and may not be generalized to the population.

Participants were merely asked whether or not they had engaged in certain behaviors, they were not asked to indicate the frequency of participation. 
Participants were not asked how recently they engaged in these behaviors.

These questions were not asked because it would have made the instrument unwieldy and could have perhaps changed the way the participant answered the questions. This type of data was not germane to the research questions, but is certainly a consideration for future studies.

\section{Definition of Terms}

For the purpose of this paper, unethical behaviors are defined as participation in cheating, falsification or fabrication of work, plagiarism or violation of the Nurse Practice Act. Some examples of such behaviors are copying from another person's test, making up data for reports or client records, submitting others' work without giving credit to that source, breaking client confidentiality, taking supplies, failing to report a medication error, and recording treatments as completed when in actuality they were not done. The term does not refer to broad areas of ethics such as right to die, abortion or cloning issues. The terms academic misconduct and cheating are similar and are sometimes substituted for unethical behaviors in the college setting.

The nursing student experience refers to the time that an individual is enrolled in a school of nursing. This may be a baccalaureate or an associate degree program or a hospital-based diploma program. This experience typically consists of two components. The classroom setting is where the theoretical basis for client care is taught. The clinical setting is one in which the individual applies what is learned in the classroom to actual client care. The clinical setting is 
typically an acute care facility, but may include such areas as home care, nursing homes, or outpatient clinics. The term initial nursing education refers to the individual's nursing education which enabled them to become eligible for licensure. Students with diplomas in nursing or associate degrees in nursing frequently return to college to receive a bachelor's degree in nursing.

The registered nurse is an individual who has graduated from a school of nursing and has passed a licensure examination administered by a state board of nursing. The term workplace refers to the setting in which the registered nurse is employed and participates in the care of clients.

\section{$\underline{\text { Summary }}$}

Use of unethical behaviors occurs in schools of nursing. The extent to which use of these behaviors carries over into the workplace has not been studied. If unethical behaviors are used in the workplace, there may be a resultant detrimental effect on client care. This study seeks to determine if there is a relationship between use of unethical behaviors as a nursing student and as a registered nurse. In addition, the relationship between the severity of unethical behaviors utilized in the nursing student experience and the workplace will be studied. 


\section{Chapter 2}

\section{Review of the Literature}

There is a large body of work that relates to unethical behavior. In this section, studies which address why students cheat, the incidence of cheating, and the prevention of cheating will be reviewed. Research relevant to student and faculty perceptions of cheating as well as reactions to cheating will be included. Finally, studies related of dishonesty in the workplace will reviewed. Student and Faculty Perceptions of Cheating Behaviors

In order to analyze participation in cheating behaviors, it must first be established what constitutes cheating behaviors. Numerous surveys of students' perceptions of cheating are reported in the literature. Most of the surveys asked students to rate behaviors as either honest or dishonest. The student populations for these surveys included business majors, nursing students, and students in most other courses of study. Several themes emerge when examining the studies done related to perceptions of cheating.

The first theme to emerge is falsification of work. Students in all fields generally rate the following behaviors as cheating: taking a test for someone else, giving answers to another student during a test, receiving answers from another student during a test (Barnett \& Dalton, 1981; Harnest, 1986; Hilbert, 1985; Stern \& Havlicek, 1986, Stevens \& Stevens, 1987; Sutton \& Huba, 1995) and using notes during an exam (i.e. crib sheets) (Barnett \& Dalton, 1981; Harnest, 1986; Hilbert, 1985; Stern \& Havlicek, 1986, Stevens \& Stevens, 1987;; 
Sutton \& Huba, 1995). Other test taking behaviors which are seen as cheating included having another student take a test (Harnest, 1986) and giving and receiving test answers through the use of signals (Barnett \& Dalton, 1981; Sutton \& Huba, 1995). Students also may submit papers which are not their own work, whether they are written by another student (Barnett \& Dalton, 1981; Harnest, 1986; Hilbert, 1985; Stern \& Havlicek, 1986; Stevens \& Stevens, 1987; Sutton \& Huba, 1995) or a commercial firm (Barnett \& Dalton, 1981; Harnest, 1986; Hilbert, 1985; Stern \& Havlicek, 1986, Stevens \& Stevens, 1987; Sutton \& Huba, 1995).

Sutton and Huba (1995) reported that students' perceptions of what were and were not cheating behaviors did not vary between African American and White students. In addition, they also examined student perceptions of cheating behaviors as related to the student's participation in religious activities. Results indicated that students who were more involved in religious activities were more likely to rate the following falsification behaviors as cheating behaviors: adding items to a bibliography when they were not used in the paper, working together on an assignment when it was not permitted by the instructor, and copying sentences into a paper without footnoting the source.

Stern and Havlicek (1986) surveyed 314 students whose major area of study was not identified. This study's results indicated that $71 \%$ of students rated adding items to a bibliography that were not used in the paper as unethical, but only $27 \%$ thought working in a group on an individual assignment was unethical. 
Sutton and Huba (1995) surveyed 322 students whose majors were not identified. They found that between $25 \%$ and $35 \%$ of students enrolled in a variety of majors considered the following behaviors to be cheating: copying some sentences from a source and not footnoting the source, adding items to a bibliography that were not utilized in writing the paper, and working with other students on an assignment when this was not permitted by the instructor. These same behaviors were included in a survey done by Hilbert (1985) utilizing 101 nursing students and were rated as cheating by $60-80 \%$ of the students. Stevens and Stevens (1987) surveyed 210 business students and reported that plagiarism and falsifying a bibliography were scored as basically unethical behaviors.

Instances where the student is able to falsify information are not limited to the classroom setting. Stern and Havlicek (1986) reported that $73 \%$ of students consider faking the results of an experiment in which correct results were not obtained to be cheating. Writing a laboratory report for an experiment that was not actually done was considered cheating by $71 \%$ of students, and $71 \%$ also thought that delaying taking an exam or turning in an assignment by giving a false excuse was cheating.

In the clinical area, Hilbert (1986) reports that nursing students considered documenting treatments, medications or observations as completed when they were not done as unethical. Behaviors which were also considered unethical were not reporting breaking something that belonged to a client, 
failing to report an incident that was client related or calling in sick when the student was not sick. Hilbert's work is supported by Harnest (1986) who surveyed both nursing faculty and students regarding their perceptions of unethical behavior. Other examples of unethical behavior in the clinical area included recording home visits that the student had not actually done.

Professionalism in nursing is another theme that can be found in the literature when examining cheating or unethical behaviors. Behaviors which were described as unethical included coming to the clinical area under the influence of drugs or alcohol, discussing clients in public areas of the hospital (Hilbert, 1985), attempting to do a procedure when the student was unsure about it, and using contaminated equipment (Harnest, 1986). A smaller percentage thought that coming to the clinical area unprepared was unethical (Harnest, 1986). The percentage of students who thought stealing was unethical varied by what items were taken. Hilbert (1985) found that a high frequency of students thought that taking medication was unethical, but fewer students thought eating food intended for a client, or taking hospital equipment for the student's own use was unethical.

Students and faculty also generally agreed about what constitutes cheating. Areas of falsification, such as taking an exam for another student, copying from another student's paper, submitting someone else's paper as their own work were considered cheating by both students and faculty (Harnest, 1986; Nuss, 1984; Stern \& Havlicek, 1986). Nuss had faculty and students rank 
cheating behaviors in order of severity. Faculty and students ranked the same behaviors on both ends of the scale, most severe and least severe. The highest ranked behaviors included either taking a test for another or having a student take a test for them, altering university documents, submitting another students' work as one's own, and copying from another student's test. The behaviors ranked as least severe included padding the bibliography, working in a group on an assignment that was an individual assignment, and copying sentences from a source without citing the source. Later work by Tom and Borin (1988) and Sims (1995) support those findings. Harnest (1986) had faculty and students review a list of behaviors and evaluate each one as being honest or dishonest. The resulting data in the study did not differentiate the perceptions of faculty and students. However, the high percentage of respondents who considered certain behaviors as unethical might be interpreted as agreement on these behaviors. The areas with an agreement percentage rate of $98 \%$ or higher included falsification of records, not reporting errors, not reporting damaged client property and attempting to do a procedure without appropriate knowledge. Coming to the clinical area without being prepared for the assignment has the lowest frequency of being considered unethical behavior. In addition, Harnest reported faculty had less variation in what they considered to be unethical behaviors and perceived more behaviors as dishonest than the students did. This is supported by Stevens and Stevens (1987), who reported that they found 
that students thought that their own ethical standards were high, but they perceived faculty standards to be higher.

\section{Why Students Cheat}

Students report various reasons why they engage in cheating behaviors.

One of the main reasons that students cheat is related to the pressure to get good grades. This pressure is generated by parents or the desire to succeed (Barnett \& Dalton, 1981; Hilbert, 1987; Payne \& Nantz, 1994; Stevens \& Stevens, 1987). Students feel that they need high grades in order to successfully enter competitive programs such as medical school. Hilbert further elaborated that some students indicated they cheated because they desired to be considered successful by others whose opinions they valued. Stevens and Stevens reported that students feel that cheating makes efficient use of the student's time and requires little effort. Daniel, Adams and Smith (1994) stated that students believe that their participation in cheating is acceptable because it will help raise their GPAs and thus assist them in the competitive job market.

Peer pressure is an area where there are conflicting results related to why cheating occurs. Payne and Nantz (1994) reported that a high percentage of students cheat due to peer pressure, students expect their friends to help them. Students in the research conducted by Stevens and Stevens (1987) did not rate peer pressure as a frequent reason why cheating occurs. Barnett and Dalton (1981) indicate that most students have only mild disapproval of their friends' participation in cheating behaviors. 
Students' perceptions related to cheating also are reasons why they cheat. Students do not always consider the behavior they engage in to be unethical. In Hilbert's study (1987), students reported that the main reason they cheated in the clinical area was that the behavior did not seem to be unethical. These students also indicated that this was also a reason for cheating in the classroom, but with a smaller frequency. Studies by Stevens and Stevens (1987) and Payne and Nantz (1994) also support this reason for cheating. The students' perception that the risk of getting caught cheating is low also plays an important role in a student's participation in cheating behaviors (Stevens \& Stevens; Payne \& Nantz). Nursing students concur that this is a reason why cheating occurs in the clinical area (Hilbert, 1987). In fact, Haines, Diekhoff, LaBeff and Clark (1986) reported that only $1.3 \%$ of students indicated that they had been caught cheating. Additionally, students may perceive that others are not harmed by their cheating, after all it is only a grade on a test or paper (Payne \& Nantz, Stevens \& Stevens). Finally, students indicate that they cheat because they feel that the course or assignment is not relevant to their major or it is unlikely that they will learn anything from it. (Hilbert; Payne \& Nantz; Stevens \& Stevens).

Environmental factors sometimes play a role in cheating. A study by Uhlig and Howes (as cited in Bradshaw \& Lowenstein, 1990) described that a high percentage of students will cheat when an opportunity presented itself. A study by LaBeff, Clark, Haines and Diekhoff (1990) supports this premise. 
A survey of chief student affairs officers (CSAOs) was conducted by Aaron and Georgia (1994). Results from this study indicate that the CSAOs perceived cheating to be related to these factors: plagiarism occurs because students are not aware of what constitutes plagiarism, there is an increase in cheating when students perceive that grading practices or tests are unfair, and the likelihood that a student will cheat increases when fellow classmates cheat.

It is not only important to examine why students cheat but also how this is related to the students own moral development. Hilbert (1988) examined the relationship between the level of moral development of nursing students and unethical behaviors in the classroom and clinical areas. Kohlberg's theory of moral stages was used as a framework for this study. Kohlberg describes moral stages which develop over time. Each stage is more complex and assists the individual to resolve moral conflict and devise guides to action. As an individual progresses through the stages they are believed to act more morally than they did at an earlier stage. Blasi (as cited in Hilbert) describes reasons why an individual may not engage in cheating behaviors at different levels in Kohlberg's theory. The fear of being caught may deter a Stage 2 individual, whereas societal norms and a desire to conform may keep a Stage 3 individual from cheating. Individuals in higher levels may not cheat because of the need to maintain trust among that individual and others. Hilbert hypothesized that there was an inverse relationship between the level of moral development and cheating in the classroom. Data from the study did not support this hypothesis. 
However, there was a significant inverse relationship between an individual's level of moral development and unethical behaviors in the clinical area. Hilbert notes that one possible explanation for this is the fact that in the classroom setting, students may not perceive cheating as harming anyone. In the clinical area, students are able to see the effect of their actions on clients.

Unfortunately, Hilbert noted, students do not relate the fact that cheating on a test or an assignment may lead to their lack of knowledge about how to care for a client. Peterson (1986) also examined cheating in light of Kohlberg's theory. In this study, students described reasons why they would or would not turn in a paper that was done as a collaborative effort rather than an individual effort as assigned. Kohlberg's stages of moral development were used to classify the reasons for cheating or not cheating. The students' moral development levels included all six stages, with the majority of responses being classified as Stage 3 or lower. The students were motivated by either fear of punishment or the desire to conform, rather than the morality of the behavior.

Gilligan (1982) presented another theory by which the morality of behavior can be examined. Kohlberg's work was done with men, whereas Gilligan realized that were differences in how women made moral decisions. Gilligan believed that women make moral choices from a relational perspective. One moves from a more self centered approach to one in which the needs of self and others are considered in decision making. This has been term the ethic of care. Kohlberg's theory has a justice orientation rather that a care approach. 
Millette (1994) conducted a research study in which nurses described ethical decisions they had made. The majority of the decisions had a caring perspective, although elements of a justice perspective were present in some. Hoyer, Booth, Spelman \& Richardson (1991) have designed a tool using clinical indicators as a means of assessing moral development of nursing students. They used both Kohlberg and Gilligan as the framework for the tool's development so that students of either gender could be assessed. Once student's moral development is assessed, then a learning environment can be created in order to enhance the moral development of nursing students.

Another theory which has been used as a framework for examining cheating behaviors is the concept of neutralization. Sykes and Matza (1957) describe the neutralization process as a way of justifying behaviors that are against the norms of society. The individual recognizes that the behavior is not acceptable, however special circumstances permit the individual to violate the norm. This then frees the individual from considering themselves guilty of wrongdoing. This thought process can occur before, during or after participating in the unacceptable behavior.

Haines, Diekhoff, LaBeff, and Clark (1986) utilized this framework in a research study. They analyzed data from questionnaires from 380 undergraduate students. More than $50 \%$ of the students completing the questionnaire indicated that they had participated in some form of cheating. Included in the questionnaire were hypothetical statements that represented the 
five types of neutralization techniques described by Sykes and Matza. Students who cheated had higher levels of neutralization than those who did not. In addition, the group who cheated indicated that they were most likely to be deterred from cheating by the consequences of being caught or by disapproval of others. This correlates with the lower levels of moral development in Kohlberg's theory. The questionnaires that the students completed also had a section in which open-ended responses were elicited. These responses were analyzed by the same authors in a later work (LaBeff, Clark, Haines \& Diekhoff 1990). In this analysis, responses were examined utilizing the five types of neutralization categories described by Sykes and Matza. The first category relates to denial of responsibility, or in other words, it wasn't the students fault that they cheated but the cheating occurred due to circumstance that they could not control. LaBeff et al. found students identified this response most frequently. Responses indicating there was too much required reading, the student had to work, or the student was sick and missed class fit into this category. Other responses indicated that the student had tried to pass the course without cheating, but had not been successful and saw cheating as the only way to pass. Other students indicated that they had not intended to cheat, but the opportunity just presented itself. In one instance, the student's neighbor had left their answer sheet uncovered, and because the answers were then in plain view, it was hard not to cheat. 
Students indicated they cheated because their friends were in need.

These reasons relate to the second category of appealing to higher loyalties. Students describe special circumstances, for example, their friends had been sick and needed help, as making cheating acceptable in that instance. This relates also to peer pressure as described earlier in this review.

A third category of neutralization is condemnation of condemners. Here, the students shift attention from themselves to those in authority. The students often categorize the teacher as being dishonest in some way, such as being unfair in grading practices or unethical in their teaching. Students wrote about their beliefs that some instructors make exams difficult with the intent of tricking students rather than testing knowledge, others indicated that the teachers were uncaring and not helpful, leading students to cheat.

LaBeff et al. (1990) report that the last two categories, denial of injury and denial of the victim were not described by students in their accounts of cheating. The authors surmise that since there are no real targets in cheating it is unlikely that these categories would appear in students accounts of cheating. In support of this premise, work by Stevens and Stevens (1987) and Payne and Nantz (1994) reported that students have indicated that they felt that no one was really harmed by cheating.

In contrast, in Hilbert's (1988) study of moral development, she indicated that one possible explanation that students cheated less in the clinical area 
related to the fact that they could see the effect of their actions on clients, whereas on a test, it was hard to see who was hurt by cheating.

Although some students feel that cheating is justified because of special circumstances, other students feel that cheating is never justified. Barnett and Dalton (1981) examined student and faculty attitudes related to cheating. About $75 \%$ of the students surveyed agreed that cheating was not justified under any circumstance. In contrast, $98 \%$ of the faculty indicated that there were no circumstances in which cheating was justified. In the same survey, $14 \%$ of the students agreed that cheating was justified when a student needed to pass a course in order to stay in school, whereas less that $2 \%$ of faculty agreed with this statement. Jendrek (1992) found that $84 \%$ of students disagreed with a statement that said that cheating was justified under some circumstances. In this same study, only $8 \%$ of students agreed that cheating was justified when a student needed to pass a course. A later study by Sutton and Huba (1995) supports some of these findings. In this study, $74 \%$ of students agreed that cheating is not justified under any circumstances. Of those students who thought that cheating is justified under special circumstances, most indicated that needing a course for graduation or to stay in school was a justification for cheating.

Incidence of Cheating

There are numerous studies related to the incidence of cheating and a wide variation is found in the percentages of students who participated in some 
type of cheating behavior. All the data in these studies is self-reported by the students. In 1980, Baird administered a questionnaire about cheating to 200 students at a state college. A high percentage of these students $(89.5 \%)$ admitted that they had cheated some time during their years in the educational system, with $75.5 \%$ indicating that they had cheated during college studies. Some students (43\%) admitted that they cheated in courses in which they were presently enrolled. In a study conducted by Haines et al. (1986) at a small state university, 380 undergraduate students completed a questionnaire related to cheating. The overall cheating percentage was $54 \%$. In contrast, Davis, Grover, Becker, and McGregor (1992) surveyed more that 6,000 students in 35 schools. The schools included large and small state schools, large and small private schools and two year colleges. The prevalence ranged from a low of $9 \%$ reported by women at a small private college to a high of $64 \%$ reported by men at a small university. In 1993, Sims surveyed sixty graduate students enrolled in a business course. The reported rate of cheating by those students in their undergraduate course of study was $91 \%$.

There are also variations in how the different types of cheating behaviors are examined. Some studies broke down cheating into broad areas such as major tests, quizzes or assignments, and others were very specific, such as copying from another student or taking a test for another student. In the area of cheating on major exams, Baird (1980) reported that $58.5 \%$ of students were involved in cheating on unit exams and Haines et al. (1986) reported that $23.7 \%$ 
students participated in this form of cheating. In contrast, Stern and Havlicek (1986) reported $71 \%$ participation. Hilbert conducted three separate studies with nursing students and the results varied. In 1985, the rate of cheating on tests was $9 \%$, in 1987 it was $23 \%$ and rose to a high of $33 \%$ in 1988 . In the area of cheating on quizzes, Baird reports $43 \%$ of students participated in this type of behavior. Haines et al. (1986) indicated a rate of cheating at $22 \%$. In cheating related to assignments, Haines et al. indicate $34 \%$ of students report that they have cheated. In comparison, Hilbert (1987) reported a low of $13 \%$ of students worked with others on an individual assignment and a high of $52 \%$ students who copied a few sentences from a reference without citing the source (1987). Stern and Havlicek (1986) indicated that $40 \%$ of students reported that they padded the bibliography, and $27 \%$ worked in a group on an individual assignment.

Nuss (1984) reported that students indicated that they participated more in behaviors that they see as less severe forms of cheating. As described previously, students ranked cheating on exams as a more severe form of cheating than cheating on assignments. This is supported by findings in the work by Tom and Borin (1988). In examining the results of Hilbert's studies $(1985,1987,1988)$ again, the cheating percentages on examinations were much lower than the rate of cheating on assignments. The study by Stern and Havlicek (1986) contradicts Hilbert. Students in Stern and Havlicek's study ranked cheating on assignments more severely than cheating on exams. Tom and Borin indicate that there may be several reasons why students may be more 
prone to cheat in areas where they perceive cheating to be less severe. First, the severity of the cheating deters the students from participating in that behavior, or once the student is involved in a cheating behavior, their judgment of the severity of that behavior is lowered. In Hilbert's 1985 study, a comparison is made between the percentage of students who consider a behavior to be unethical and their participation in that behavior. Taking hospital equipment for one's own use was considered unethical by $65 \%$ of the students yet $59 \%$ of the students admitted that they had participated in this behavior. Discussing clients in public places was considered to be unethical by $77 \%$ of the students and $54 \%$ indicated that they had participated in this behavior. Although no ranking of these behaviors was done, many students believed a behavior to be unethical and yet still participated in that behavior.

Students perceptions of the involvement of others in cheating behaviors was the subject of some studies. Sutton and Huba (1995) described that students perceived that their peers worked as a group on individual assignments most frequently $(66 \%)$. Other behaviors which students believed their peers participated in more than $50 \%$ of the time included getting answers for exams that another student had already taken, copying sentences from a source without citing it, and copying from another student's exam without their knowledge. Sutton and Huba also examined these perceptions in relation to the ethnicity of the students. White students felt that padding the bibliography occurred more frequently than African American students. African American 
students perceived that obtaining answers for an exam from another student who had already taken it occurred more frequently than the White students' perceptions of this behavior. Bailey (1990) surveyed nursing faculty and administrators regarding cheating. They were asked if they perceived cheating to be a problem. Thirty-seven percent of faculty responded that it was a problem, $53 \%$ of administrators with less than three years experience perceived cheating to be a problem. Both groups were asked to describe two critical incidents related to cheating. The overall frequency for both groups was related to cheating on exams (37.9\%), and faculty were aware that more cheating occurs than they know about. Schmitz and Schaffer (1995) examined ethical problems encountered in the teaching of nursing. In their study, $25 \%$ of faculty and $29 \%$ of students had encountered one student's cover-up for another student's incompetence. They believed that the faculty rate should have been higher because of the number of years experience of the faculty. They surmised that this practice must occur more frequently than the faculty were aware.

When examining the incidence of cheating, researchers have examined such variables as sex, age, grade point average (GPA), major, and year in school. Baird (1980), Davis, Grover et al. (1992) and Karlins, Michaels, Freilinger and Walker (1989) report a higher incidence of cheating among males. Stern and Havlicek (1986) analyzed the frequency of student participation in thirty-six cheating behaviors and found equal participation in most instances. There was a significant difference between genders on only 
three items. For two of those items, males had a higher participation than females. Stern and Havlicek also analyzed participation in the thirty-six cheating behaviors by year in school. Students in all four years of college were equally likely to have engaged in most of those behaviors. There were seven items on the survey which demonstrated that freshmen were less likely to participate than upperclassmen. In contrast, Baird's work demonstrated that juniors were less likely to cheat, with seniors the second least likely to cheat. Sheer (1989) reports that seniors are more likely to engage in unethical behaviors than sophomores. Results of studies by Baird, Sheer, and Haines et al (1986) demonstrate that there was an inverse relationship between frequency of cheating and academic achievement. Davis, Grover et al. (1992) report that students in small liberal arts colleges indicated a lower percentage of participation in cheating than students at larger public and private schools. Haines et al. add that students who cheated are more likely to be younger than non cheaters, single, and be receiving financial support from their parents.

Sheer (1989) studied personality dimensions as a predictor of unethical behaviors of student nurses in the classroom and clinical settings. Classroom unethical behaviors could not be predicted by personality profiles. Participation in unethical clinical behaviors could be predicted by personality profiles.

Students who were categorized as low in socialization and had low autonomy profiles were more likely to engage in unethical behaviors in the clinical setting. 


\section{Reactions To Cheating}

Several researchers queried students about their reaction to having observed cheating by another student. Baird (1980) reported that only $1 \%$ would report the cheating incident, $40.5 \%$ would not report the incident and wouldn't be disturbed by it, and $40 \%$ would do nothing but would be disturbed by the incident. Similar results were recorded by Nuss (1984), where $3 \%$ indicated they would report they incident. The responses changed some when the question in the survey was modified to include the qualifier of a university regulation requiring students to report cheating by other students. The percentage of students who would report another student rose to $15 \%$, while only $28 \%$ would ignore the incident. The percentage who would report the student only if they considered the cheating to be somewhat serious remained the same and $17 \%$ would not report the student but would express disapproval. The percentage of students who would ask the students who cheated to report themselves was $11 \%$.

Jendrek (1992) surveyed 776 students about their reactions to academic dishonesty. Only $1 \%$ of students indicated that they would report a student who cheats. This finding is the same as Baird's results in 1980. According to Jendrek, $74 \%$ of the students indicated that they had seen someone cheat, and $48 \%$ said that they had been asked by another student to assist them in answering questions on an examination. 
Faculty reactions to cheating vary. Nuss (1984) reported that faculty indicated that they would take action if they observed a student cheating. The student would be reported to those in authority by $39 \%$, whereas $34 \%$ would discuss the incident with the student and then lower the student's grade. The student would be given a warning by $26 \%$ and only $1 \%$ would ignore the incident.

Jendrek (1989) surveyed 337 faculty members regarding their reactions to academic dishonesty. Cheating behaviors had been observed by $60 \%$ of the faculty. The most common reaction by faculty who witnessed a student cheating on an examination was to discuss the incident with the student. $A$ joint discussion with the student and the department head was the action taken by $20 \%$ of the faculty, which was the university's policy. Only $33 \%$ reported this incident to the department head, and $8 \%$ reported the incident to the dean. The incident was ignored by $8 \%$ of the faculty. Jendrek did not ask questions about faculty knowledge about or agreement with university policy in the survey. It is not known why faculty did not follow policy. Faculty were also asked whether the student had been penalized for cheating. Approximately one third did not penalize the student. Faculty equally expressed both anger and disgust at incidents of students cheating, while fewer expressed feeling sorry for the offenders.

Faculty gave many reasons why they chose to ignore cheating. Unfamiliarity with school policy, and lack of support from administrators or peers 
are all deterrents for faculty involvement in handling cheating behaviors (Carmack, 1984). Faculty indicated lack of willingness to become involved in what may be a lengthy process which may include litigation (Davis Grover et al. 1992).

Booth and Hoyer (1992) outlined steps a nursing faculty member should take in dealing with academic dishonesty. These authors suggested that students' appeal of a grade often occurs because grading policies and grade requirements are inconsistent. Faculty should look at both these requirements and revise them as necessary. In addition, some faculty feel that it is sometimes hard to prove that a student cheated, whether the student looked at another's examination, or copied sentences from a report. In nursing, faculty often do not want to hurt the student and therefore do not always carry out the school's policy (Carmack, 1994).

Most colleges and universities have one standard policy for dealing with academic dishonesty, although there are some institutions which reported that there are variations by each department (Ludeman, 1988). In some instances the problem seems to be that the policies are not followed. Prescott (1989) stated that although there are policies, specific procedural steps must be outlined for dealing with the investigation and the process of dealing with academic dishonesty. Saunders (1993) echoed this thought. He stated that these policies should include the types of behaviors that represent misconduct, and procedures for reporting misconduct. In addition, there should be 
procedures which safeguard students who are accused of misconduct. Tauber (1984) advocated development of a disciplinary board. This would then remove decisions related to cheating from the faculty member, a responsibility that he believes never should have belonged to faculty. In addition, he advocates that the students must be made aware of their right to due process.

Aaron (1992) described a communication problem in disseminating policies for dealing with academic dishonesty. The most common methods of communicating the institutions' policies to students are the student handbook, the orientation program and the college catalog. The faculty handbook and the student handbook are the most common methods used for disseminating information to faculty. In this study, only a small percentage of faculty discussed policies in the classroom setting or in the course syllabi. Aaron stated that although most institutions have published information about cheating, this method has not been a successful way to decrease participation in unethical behaviors. Kibler (1994) suggested that faculty be more involved in developing and enforcing procedures related to academic dishonesty. He wrote that faculty "are in the best position to communicate and enforce standards and expectations." (p. 101). In addition, students should also be involved in the development and enforcement of policies about academic dishonesty. If students and faculty are both involved it will decrease an atmosphere of faculty versus students. 
Jeffreys and Stier (1995) described a communication strategy for nurse

educators. This strategy is an effective method for confronting academic misconduct and uses the acronym SPEAKING developed by Hymes (as cited in Jeffreys \& Stier). Each letter stands for an activity which should be included when confronting a student. The letter 'S' represents the situation. They advocate using a private setting when confronting the issue will the student. The 'P'articipants should involve the faculty member, the student, and possibly a third party who is neutral. this is important in that the student may initiate the grievance procedure, and the third party can be a witness in this process. The ' $E$ ' stands for ends or the institution's goals and values. 'A' represents act which relates to the discussion with the student of the accusation of dishonesty as well as the consequences for the student, client, and peers. The way in which this is communicated to the student is the ' $K$ 'ey. Included here are the tone and manner of the confrontation. The nurse educator must make every effort to remain calm and keep personal feelings such as anger out of the confrontation. The letter ' $I$ ' refers to instrumentalities or the written and oral communication used in the confrontation. The nurse educator must use clear and concise language so that no misinterpretation can be made during the confrontation. This represents the letter ' $\mathrm{N}$ ' for norms. Finally ' $\mathrm{G}$ ' stands for genre or the individual conferences used as a means of confronting the student's academic dishonesty. The model may also be used as a focus for preventing dishonesty. The communication strategy is used before any incidents of dishonesty occur. The classroom or 
clinical setting can be used by the faculty to review professional goals and school policies, and to promote discussion related to academic dishonesty. Prevention of Cheating

One of the methods that colleges utilize to discourage cheating is through the development of an honor system or an honor code. May and Loyd (1993) compared the percentage of cheating behaviors at a university with an honor system and one without. It must be noted that they did not collect the data themselves for the university without the honor system, but used statistics from a study done in 1986 by Haines et al. The overall percentage of cheating, as well as cheating on major exams, quizzes and assignments was lower in the university with the honor system. May and Loyd also examined the students' attitudes toward the honor system and participation in cheating. They found there was "no direct relationship between students' attitudes toward the honor system and the incidence of cheating or between the incidence of cheating and their opinions about the main advantages and disadvantages of the honor system." (p.128) McCabe and Bowers (1994) compared results of a survey done by Bowers in 1962 with those done by McCabe in 1991 and 1992. In both surveys, schools with an honor code had a lower percentage of student participation in cheating in both tests and written work. As a result of their study regarding academic dishonesty and honor codes, McCabe and Trevino (1993) caution that adopting an honor code in itself is not a means of deterring dishonesty. Participation in academic dishonesty is a complex behavior in which 
other variables such as peer influence play a role. Davis, Johnston, DiMarco, Findlay, and Taylor (1996) advocate that an honor code for nursing students would be an important part of the efforts of educators to foster the development of professional and personal integrity.

Other measures mentioned in the literature are specific actions an instructor might take to reduce the incidence of cheating. Activities such as multiple forms of tests and proctoring exams make cheating more difficult (Raffetto, 1985; Pactor, McKeen \& Morris, 1990). More importantly, the instructor should discuss cheating at the beginning of the course, give concrete examples of what constitutes plagiarism, and review school policies about cheating (Raffetto; Pactor et al.). Aaron (1992) suggests utilizing the campus media to publish outcomes of specific cases related to cheating might be a way of disseminating information to students and faculty about cheating. Of course, he notes, confidentiality must be protected. Another method includes giving specific directions about assignments, and whether the student is to work on the project alone or as a group. Roth and McCabe (1995) found that student awareness of the penalties for cheating is not correlated with cheating infractions. In addition, it is also not predictive of cheating behaviors. However, they found that students would assign the same penalties for cheating as faculty. The authors suggest that involving students in development of policies related to cheating might facilitate communication about cheating. 
Pratt and McLaughlin (1989) stated that the student's own ethical beliefs have the most positive effect on behavior, but are affected indirectly by their perceptions of the ethics of peers and instructors. Fosbinder (1991) advocated inclusion of ethical principles in class content. Hoyer, Booth, Spelman, and Richardson (1991) concur that students should be encouraged to take part in moral decision making as a part of the curriculum. They suggested role play, for example, as a method by which this could be accomplished. Faculty must improve their abilities to assess, facilitate, and evaluate students' moral development. In addition, Theis (1988) described students' examples of unethical behaviors exhibited by faculty. These behaviors included showing favoritism to students, allowing a student to complete a procedure using contaminated equipment, and lack of confidentiality about student matters. Faculty must take care in modeling ethical behaviors in both the classroom and the clinical setting.

\section{Dishonesty in the Workplace}

Dishonest behaviors are not limited to the undergraduate student who is trying to get a good grade to get ahead in class. An article in USA Today (Jones, April $4-6,1997)$ reported that $48 \%$ of workers surveyed admitted that they had participated in some type of unethical act. The top five unethical behaviors included covering up incidents, calling in sick when the worker was not ill, cutting corners on quality issues, lying to or deceiving customers in some way, and putting inappropriate pressure on peers. The workers cite many reasons for 
these behaviors, such as balancing family and work, lack of communication, politics in the company, and work load. The survey results indicated that workers in the health care field and manufacturing industry feel the most pressure to participate in unethical behaviors, yet they do not participate in these behaviors as much as those in the computer field.

In recent years attention has been focused on scientific misconduct. Hawley and Jeffers (1992) describe National Institutes of Health's (NIH) definition of scientific misconduct as "fabrication, falsification, plagiarism or other deviations from ethical standards" by research scientists (p. 51). Honest errors or differences in interpretation of data are not described as scientific misconduct. Holthaus (as cited in Chop \& Silva, 1991) reported that of the top fifty research institutions in the United States, one half have been investigated for fraud. Swazey, Louis and Anderson (as cited in Hansen \& Hansen, 1995) surveyed graduate schools and found that $40 \%$ of the respondents reported possible misconduct by faculty in research. Verification of scientific misconduct was reported by $20 \%$ of the respondents. In the same survey, a higher rate of reporting of and verification of scientific misconduct was found among graduate students.

The reasons for participation in scientific misconduct are numerous, and in some instances parallel reasons why students cheat. The pressure to succeed, seen as tenure and promotion by faculty contributes to scientific misconduct (Chop \& Silva, 1991; Clark, 1993; Hansen \& Hansen, 1995; Hawley 
\& Jeffers, 1992). This is not unlike an undergraduate desire to get good grades, pressure from parents, and the desire to succeed. Inadequate mentoring of beginning researchers is seen as another reason for misconduct in research (Clark; Hansen \& Hansen; Hawley \& Jeffers;). The researchers may not be aware of what constitutes misconduct, paralleling the undergraduate student's lack of recognition of what constitutes plagiarism. Other possible reasons for misconduct relate to inadequate peer review systems (Hawley \& Jeffers) or the perceived bias related to the publication of insignificant results (Clark). However, the decision to participate in scientific misconduct is that of the individual, not the fault of any system weakness (Hawley \& Jeffers). These reasons are not unlike the students who cheat and then shift the blame elsewhere.

Presently there is no evidence of nurses who have participated in scientific misconduct. Blacett (1992) described nursing editors who have discovered examples of plagiarism while reviewing manuscripts. Kelly (1984) described the tendency for the truth to be expanded or exaggerated on a resume in order to put the best light on someone's accomplishments.

Hawley and Jeffers (1992) stated that cheating does exist among nursing students. "This is disturbing in that behaviors of students may be indicative of future professional performance." (p. 116). Unfortunately, errors take place in the practice of nursing. An area of concern is the fact that attempts are made to cover-up these mistakes or at the very least not report them as required by hospitals. 
In nursing practice, a common area of study relates to medication errors. One of the areas of concern is the difference in the number of medication errors that actually occur and the reporting of such errors. It is believed that many errors go unreported. (Gladstone, 1995). One reason for this discrepancy is related to the fact that there is not agreement as to what constitutes an error and whether or not it should be reported (Baker, 1997; Gladstone; Hackel, Butt \& Banister, 1996). Nurses may fear that punitive action might by taken by the nurse manager as a results of reporting errors, and thus do not report errors (Gladstone; Hackel et al.; Wolf, Haakenson, Seeger Jablonski \& McGoldrick, 1995). Baker reported that nurses may not report errors for several other reasons. These included the belief that the error was not the nurse's fault, if it could be corrected, then it should not be reported, or that if others knew about it, it was not an error. Finally the nurse may incorrectly perceive the harm that resulted from an error (Wolf et al.). Hackel et al. reported that 146 nurses at a hospital indicated that they had made between one to two errors over a three month period, yet when official reports of errors were reviewed, only 46 reports existed. In other words, 100 to 246 errors went unreported utilizing the hospitals official form and means of dealing with errors. Fuqua and Stevens (1988) suggested that an emphasis be placed on developing a nonpunitive system of reporting errors with the result being that more errors would be reported.

NursingLife magazine conducted a study published in 1983 entitled "How Ethical Are You?" There were over 5,000 voluntary respondents in their survey. 
Of the respondents, $90 \%$ admitted that they had made a medication error. The percentage who indicated that they always completed a medication error form was $67 \%$, with $21 \%$ indicating that they only filled out the form if they thought the error was serious, and $2 \%$ admitted that they kept the error to themselves.

Nurses who added data to the nursing record by writing in empty spaces or writing between lines was $38 \%$, those who erased or altered information in the record numbered $11 \%$. Surprisingly, $14 \%$ indicated they had left out information if they felt that information would make them look bad. Nurses who falsified a client record or knew of another nurse who falsified a record to cover-up a mistake was $38 \%$. Taking hospital supplies for personal use was a common occurrence with $77 \%$ of the respondents, indicating that some nurses took supplies. Medications were taken from the hospital for personal use by over one third of the nurses who responded. The most frequent medications involved were aspirin or antacids, however, $3 \%$ have taken narcotics, and $18 \%$ indicated that they took other prescription drugs.

A few studies examined the correlation between cheating in various settings. Hilbert $(1985,1987)$ found that students who cheated in the classroom also participated in unethical behaviors in the clinical area. Sims (1993) surveyed sixty students in a graduate business course about their participation in unethical behaviors as undergraduate students and as workers. A significant relationship was found between engaging in unethical behaviors as a student and as an employee. In addition, there was a significant relationship between 
the severity of behaviors in both places. If the student engaged in what were judged to be more unethical behaviors in school, that person was more likely to engage in more severe forms of unethical behaviors in the workplace.

\section{Summary}

There is a preponderance of evidence that cheating exists in colleges and universities among all types of students. The incidence of cheating varies, but is still felt to be a problem by educators. For those involved in teaching nursing, there is concern because the student nurse will one day be involved in making decisions about client care, and those decisions have a great impact on the client's health. It is imperative that honest, ethical actions be taken by the nurse. Yet, the literature indicated that nursing students are involved in cheating, and that those behaviors in which they are engaged, although may not be high in number are serious in nature. Hilbert's $(1985,1987)$ work demonstrates a relationship between behaviors in the classroom and the clinical setting. It has also been demonstrated that nurses do participate in unethical behaviors in the workplace, as evidenced by the survey in Nursing Life ("How Ethical Are You?, 1983), and the work by Hackel et al. (1996). Work by Sims (1993) demonstrates that unethical behaviors carry over into the workplace among business professionals. It is of great concern that this carry over may also exist in nursing. 


\section{Chapter 3}

\section{Methodology}

This chapter describes the design and research procedures. This correlational study sought to examine the relationship of cheating as a nursing student and participation in unethical behaviors as a practicing nurse. This chapter includes the hypotheses, research questions, research methodology and methods for data analyses. In addition the instrument and subjects will be described.

Sample

The sample in this study consisted of registered nurses who were enrolled in either an RN to BSN program or graduate nursing program at two South Florida universities during the summer of 1997. One of the universities was a public institution and the other was a private institution. This group was chosen rather than nurses employed in a health care facility for two reasons. Participants may respond more honestly since they were not asked questions about unethical behaviors at their workplace. This would decrease any concerns they may have had that results would be reported to their employers. Secondly, health care facilities are hesitant in this time of scrutiny of the health care system to allow questions about unethical behaviors which may have occurred in their facility.

This sample encompassed nurses who were enrolled in either an RN to BSN undergraduate program or a graduate nursing program. Students in RN to 
BSN programs entered practice by completing either a diploma or associate degree program. Graduate students entered practice through an associate degree program, a diploma program or a baccalaureate program. By including both graduate students and RN to BSN students all levels of entry into practice were included in the sample.

\section{Subjects}

The subjects in the study were 148 registered nurse students who were enrolled in the summer term at the two universities selected for the study.

Students in several classes were asked to participate in the study. An attempt was made to balance the number of students enrolled in RN to BSN classes with those enrolled in graduate courses. In addition, the researcher tried to balance the number of students enrolled in a public university with the number enrolled in the private university.

Not every student who was enrolled in a summer course participated in the study, as a representative group was sought. Classes were selected by those in which the faculty member would permit class time to be used for the survey. In addition, classes were selected according to the availability of the researcher's schedule. Finally, some classes were not visited in order to keep the number of students in each group equal.

\section{$\underline{\text { Instrument }}$}

The Self Report of Unethical Behaviors Inventory (SRUEBI) was used as the instrument in this study (See Appendix A). It consisted of 56 self-reported 
identified. It was hoped that this would increase the likelihood that subjects answered the questions truthfully.

Once the instrument was developed, it was reviewed by nursing faculty for content validity. A few items were modified for clarity. A pilot study was done with this instrument to establish reliability. A group of 20 students was asked to complete the survey. Two weeks later, this same group of students was asked to again complete the questionnaire. The two scores were correlated for test-retest reliability which was $\underline{r}=.674, p<.001$. Although a higher reliability might be desirable, the researcher considered the following circumstances in accepting this value. First, this was a very sensitive topic. After admitting to participating in unethical behaviors the first time the questionnaire was completed, the participant may have had second thoughts about reporting behaviors when completing the questionnaire a second time. Secondly, it is not known what topics were discussed in class immediately before the questionnaire was administered either time. Cronbach alpha was utilized to compute the internal consistency and this value was $\underline{r}=.861, \underline{p}<.001$.

Items from the instrument which pertained to unethical behaviors in the nursing student experience were distributed to twenty nursing faculty who were asked to rate the severity of behaviors (See Appendix B). Faculty from associate degree and baccalaureate programs served as nurse experts. Faculty from the two universities used in the study served as experts. In addition, twenty nurse administrators were asked to rate the severity of behaviors for items which 
pertained to practicing nurses (See Appendix C). All severity ratings for behaviors were determined using a 5 point Likert scale, with 1= not unethical, 2 $=$ slightly unethical, $3=$ somewhat unethical, $4=$ moderately unethical and $5=$ severely unethical. The mean for each item was then calculated from their responses. The severity score for each item was determined to be the whole number closest to the mean, median and mode.

\section{Design of the Study}

This correlational study was designed in order to examine the relationship between several variables, engaging in unethical behaviors in the classroom, engaging in unethical behaviors in the clinical setting and engaging in unethical behaviors in the workplace. Additionally, the relationship between the severity of unethical behaviors utilized in all three settings was examined. Other variables which were of interest in this study were years in nursing practice, type of initial nursing education, whether or not they were raised in the United States and the relationship of those variables to participation in unethical behaviors.

\section{Procedure}

Permission from the Investigational Review Board for both institutions was obtained. A schedule of classes was obtained from each institution and permission for the researcher to come to class was obtained from the faculty member teaching the class.

The researcher or her designee distributed the consent, cover letter and questionnaire to each class. Instruments were color coded so that the 
researcher could identify whether the class was a graduate or undergraduate class and from which institution. No numerical markings were placed on the instruments. Because of the nature of the questions, the cover letter was stapled to the instrument, thus allowing some measure of privacy for the subject. The subject was asked minimal demographic information in the effort to increase participation in the study. The instruments were distributed to the subjects and collected by the researcher or her designee in a manila envelope.

Once the surveys were completed, data was entered into the computer utilizing SPSS for Windows. Data was analyzed for frequency, percentages, mean and standard deviation for overall participation in unethical behaviors as well as for participation in the classroom, clinical and workplace settings, and reported unethical behavior of peers. Scatter plots for the percentage of unethical behaviors used in classroom versus clinical, classroom versus workplace, clinical versus workplace and overall student experience versus workplace were drawn. Correlation coefficients for these same comparisons were calculated. The weighted scores for severity in all three settings (classroom, clinical, workplace) were calculated and correlation coefficients were determined. McNemar's Test was used to match usage of unethical behaviors in one setting to another, such as student clinical to workplace. In addition, one way ANOVAs and $\underline{t}$ tests were performed on the usage of unethical behaviors as measured by percentages of use by demographic variables. 
$\underline{\text { Summary }}$

This correlational study analyzed the relationship between participation in unethical behaviors in three settings (classroom, clinical, workplace). The relationship between the severity of behaviors utilized in those settings was also investigated. A 59 item questionnaire was developed for this study. After reliability and validity were established, the instrument was distributed to 148 students enrolled in RN to BSN or graduate nursing classes. Data was then analyzed using inferential statistics such as t tests, correlational tests, and one way ANOVA. McNemar's Test was used to compare matched items. Descriptive statistics such as frequency, percentages, mean and standard deviation were also calculated. 


\section{CHAPTER IV}

\section{Results}

The purpose of this study was to examine the relationship between registered nurses' use of unethical behaviors in the classroom or clinical setting during their nursing student experience and their participation in unethical behaviors in the workplace as registered nurses. Additionally, the relationship between the severity of unethical behaviors utilized in the classroom, clinical setting and those in the workplace were examined. Data were also analyzed to answer several research questions concerning the relationship between the use of unethical behaviors in all settings and demographic variables.

In this chapter the results of the data analysis are presented. The chapter begins with an analysis of the demographic data provided by the participants. The next section of the chapter presents and analyzes data as it pertains to the hypotheses and research questions. Finally, a brief summary of the findings is presented.

\section{Analysis of Demographic Data}

The population in this study consisted of 148 students enrolled in nursing classes during the summer of 1997 . All were registered nurses who were pursuing either a bachelor's or master's degree in nursing. They were enrolled in either a public or private institution and were in either undergraduate or graduate nursing classes. Participants who completed the questionnaires were asked to indicate the type of initial nursing education they had, the number of years they 
had been in nursing and whether they spent the majority of time from birth to age 18 in or outside the United States. A small number of students did not complete the demographic data. Frequencies and percentages were found for overall participant data (See Table 1).

The majority of the participants $(56 \%, \underline{n}=80)$ indicated that they had entered nursing through an associate degree program. Diploma school graduates ( $\underline{n}=22$ ) accounted for $22 \%$ of the participants and $22 \%$ entered nursing practice as baccalaureate graduates $(\underline{n}=31)$. Nurses with one to five years of experience ( $\underline{n}=32$ ) comprised $22 \%$ percent of the participants, whereas nurses with six to ten years experience $(\underline{n}=34)$ comprised $23 \%$ of the participants. There were 10 nurses $(7 \%)$ who had less than one year experience, and 19 nurses (13\%) who had over 21 years experience. The rest of the participants had either $11-15$ years experience $(\underline{n}=28,19 \%)$ or $16-20$ years experience ( $\underline{n}=22,15 \%)$. Sixty-two percent of the participants $(\underline{n}=90)$ indicated that they had spent the majority of time from birth to age eighteen in the United States. Nurses $(n=54)$ who spent the majority of time from birth to age 18 outside the US comprised $37 \%$ of the participants.

The demographic data was broken down by type of current enrollment (See Table 2). Graduates of associate degree programs accounted for the largest number of students $(\underline{n}=53)$ enrolled in the undergraduate programs used in the study. The number of graduates of associate degree programs ( $\underline{n}=27$ ) and baccalaureate programs $(\underline{n}=29)$ was approximately equal for the current 
Table 1

Demographic Profile of Students $(\underline{N}=148)$

\begin{tabular}{|c|c|c|}
\hline & $\underline{n}$ & $\%$ \\
\hline $\begin{array}{l}\text { Basic Nursing Preparation } \\
\text { Associate Degree }\end{array}$ & 80 & 54.1 \\
\hline Diploma & 32 & 21.6 \\
\hline Baccalaureate Degree & 31 & 20.9 \\
\hline No Response & 5 & 3.3 \\
\hline Total & 148 & 100.0 \\
\hline Years of Practice & & \\
\hline$<1$ & 10 & 6.8 \\
\hline $1-5$ & 32 & 21.6 \\
\hline $6-10$ & 34 & 22.9 \\
\hline $11-15$ & 28 & 18.9 \\
\hline $16-20$ & 22 & 14.9 \\
\hline over 21 & 19 & 12.8 \\
\hline No Response & 3 & 2.0 \\
\hline Total & 145 & 100.0 \\
\hline $\begin{array}{l}\text { Time between birth and } \\
\text { age } 18\end{array}$ & & \\
\hline in the US & 90 & 60.8 \\
\hline outside the US & 54 & 36.5 \\
\hline about $50 \% / 50 \%$ & 2 & 1.4 \\
\hline No Response & 2 & 1.4 \\
\hline Total & 146 & 100.0 \\
\hline
\end{tabular}


Table 2

Demographic Profile of Students By Current Enrollment $(\underline{N}=148)$

\begin{tabular}{|c|c|c|c|c|c|c|c|c|}
\hline & \multicolumn{2}{|c|}{$\begin{array}{c}\text { Undergrad } \\
\text { Public }\end{array}$} & \multicolumn{2}{|c|}{$\begin{array}{c}\text { Undergrad } \\
\text { Private }\end{array}$} & \multicolumn{2}{|c|}{$\begin{array}{c}\text { Graduate } \\
\text { Public }\end{array}$} & \multicolumn{2}{|c|}{$\begin{array}{c}\text { Graduate } \\
\text { Private }\end{array}$} \\
\hline & $n$ & $\%$ & $\mathrm{n}$ & $\%$ & $n$ & $\%$ & $n$ & $\%$ \\
\hline $\begin{array}{l}\text { Previous } \\
\text { Education }\end{array}$ & & & & & & & & \\
\hline$A D N$ & 28 & 84.8 & 25 & 69.4 & 14 & 37.8 & 13 & 35.1 \\
\hline Diploma & 3 & 9.1 & 11 & 30.6 & 8 & 21.6 & 10 & 27.0 \\
\hline BSN & 2 & 6.1 & 0 & 0.0 & 15 & 40.5 & 14 & 37.8 \\
\hline $\begin{array}{l}\text { Total } \\
\text { (No Response } \\
=3 \text { ) }\end{array}$ & 33 & 100.0 & 36 & 100.0 & 37 & 100.0 & 37 & 100.0 \\
\hline $\begin{array}{l}\text { Years of } \\
\text { Practice }\end{array}$ & & & & & & & & \\
\hline$<1$ & 6 & 17.6 & 2 & 5.7 & 1 & 2.6 & 1 & 2.6 \\
\hline $1-5$ & 9 & 26.5 & 6 & 17.1 & 10 & 26.3 & 7 & 18.4 \\
\hline $6-10$ & 10 & 29.4 & 7 & 20.0 & 11 & 28.9 & 6 & 15.8 \\
\hline $11-15$ & 7 & 20.6 & 9 & 25.7 & 5 & 13.2 & 7 & 18.4 \\
\hline $16-20$ & 2 & 5.9 & 6 & 17.1 & 4 & 10.5 & 10 & 26.3 \\
\hline over 21 & 0 & 0.0 & 5 & 14.3 & 7 & 18.4 & 7 & 18.4 \\
\hline Total & 34 & 100.0 & 35 & 100.0 & 38 & 100.0 & 38 & 100.0 \\
\hline
\end{tabular}

Note: continued on next page 
Table 2 (con't)

\begin{tabular}{|c|c|c|c|c|c|c|c|c|}
\hline & \multicolumn{2}{|c|}{$\begin{array}{c}\text { Undergrad } \\
\text { Public }\end{array}$} & \multicolumn{2}{|c|}{$\begin{array}{l}\text { Undergrad } \\
\text { Private }\end{array}$} & \multicolumn{2}{|c|}{$\begin{array}{c}\text { Graduate } \\
\text { Public }\end{array}$} & \multicolumn{2}{|c|}{$\begin{array}{c}\text { Graduate } \\
\text { Private }\end{array}$} \\
\hline & $\underline{n}$ & $\%$ & $\underline{n}$ & $\%$ & $n$ & $\%$ & $\underline{n}$ & $\%$ \\
\hline \multicolumn{9}{|l|}{$\begin{array}{l}\text { Time between } \\
\text { birth and age } \\
18 .\end{array}$} \\
\hline in the US & 22 & 64.7 & 22 & 61.1 & 21 & 55.3 & 25 & 65.8 \\
\hline $\begin{array}{l}\text { outside the } \\
\text { US }\end{array}$ & 12 & 35.3 & 14 & 38.9 & 16 & 42.1 & 12 & 31.6 \\
\hline $\begin{array}{c}\text { about } 50 \% \\
\quad / 50 \%\end{array}$ & 0 & 0.0 & 0 & 0.0 & 1 & 2.6 & 1 & 2.6 \\
\hline $\begin{array}{l}\text { Total } \\
\text { ( No } \\
\text { Response = 2) }\end{array}$ & 34 & 100.0 & 36 & 100.0 & 38 & 100.0 & 38 & 100.0 \\
\hline
\end{tabular}


graduate level enrollees. Years of practice varied very little by type of educational enrollment. One main difference occurred in those participants with less than one year of practice. Only two participants were currently enrolled in graduate programs. In the undergraduate programs there were eight participants with less than one year of experience. Most graduate programs require one or more years of nursing practice before a student can matriculate into the program. There were somewhat more private undergraduate participants with 16 or more years of experience $(31.4 \%)$ than public undergraduate participants (5.9\%). There was little difference in the percentage of participants who spent the majority of time from birth to age eighteen in the United States among the four types of current educational enrollment. These ranged from 55 to $60 \%$. Similarly, there was little difference among the groups related to spending the majority of time from birth to age eighteen outside the United States with percentages ranging from 32 to $42 \%$.

\section{Frequency of Participation in Unethical Behaviors}

The first research question examined the frequency of participation in unethical behaviors in each of the three settings (classroom, clinical and workplace). A total of 24 items on the questionnaire were related to unethical behaviors that nursing students may have utilized. These behaviors were divided into two categories, classroom related behaviors, and student clinical experience behaviors. Items 1 through 10 were considered classroom related 
behaviors and items 11 through 24 were related to the student clinical

experience. The number of unethical behaviors reported in the classroom setting ranged from none to a high of six, with a mean of $1.26(\underline{S D}=1.44)($ See Table 3). The range of number of behaviors reported in the student clinical experience ranged from none to nine, with a mean of $2.49(\underline{\mathrm{SD}}=2.12)$. Forty-two percent of the participants $(\underline{n}=62)$ reported that they did not use any unethical behaviors in the classroom setting. The percentage of participants who reported they did not use any unethical behaviors during their student clinical experience dropped to $18 \%$ of the participants $(\underline{n}=26)$. More participants reported using unethical behaviors in the student clinical experience than in the classroom. The percentage of participants who reported they did not use any unethical behaviors either in the classroom or clinical during their student experience was $11 \%(\underline{n}=17)$.

In the classroom setting, $21 \%$ of the participants $(\underline{n}=31)$ reported that they utilized one unethical behavior, and $20 \%$ used two unethical behaviors $(n=30)$. These findings are similar to those in the clinical setting where $20 \%$ reported use of only one unethical behavior $(\underline{n}=30)$, and $24 \%$ reported use of two unethical behaviors ( $\underline{n}=35)$. Only $8 \%$ of participants $(\underline{n}=11)$ reported that they had utilized four to six unethical behaviors in the classroom, this percentage rose $23 \%$ of participants $(\underline{n}=34)$ in the student clinical setting. Nine percent of the participants $(\underline{n}=13)$ reported that they had participated in six or more behaviors in the clinical setting. No participants indicated using six or more 
Table 3

Frequency of Reported Use of Unethical Behaviors in the Classroom and

\section{Clinical Setting}

Classroom

Number of

Behaviors

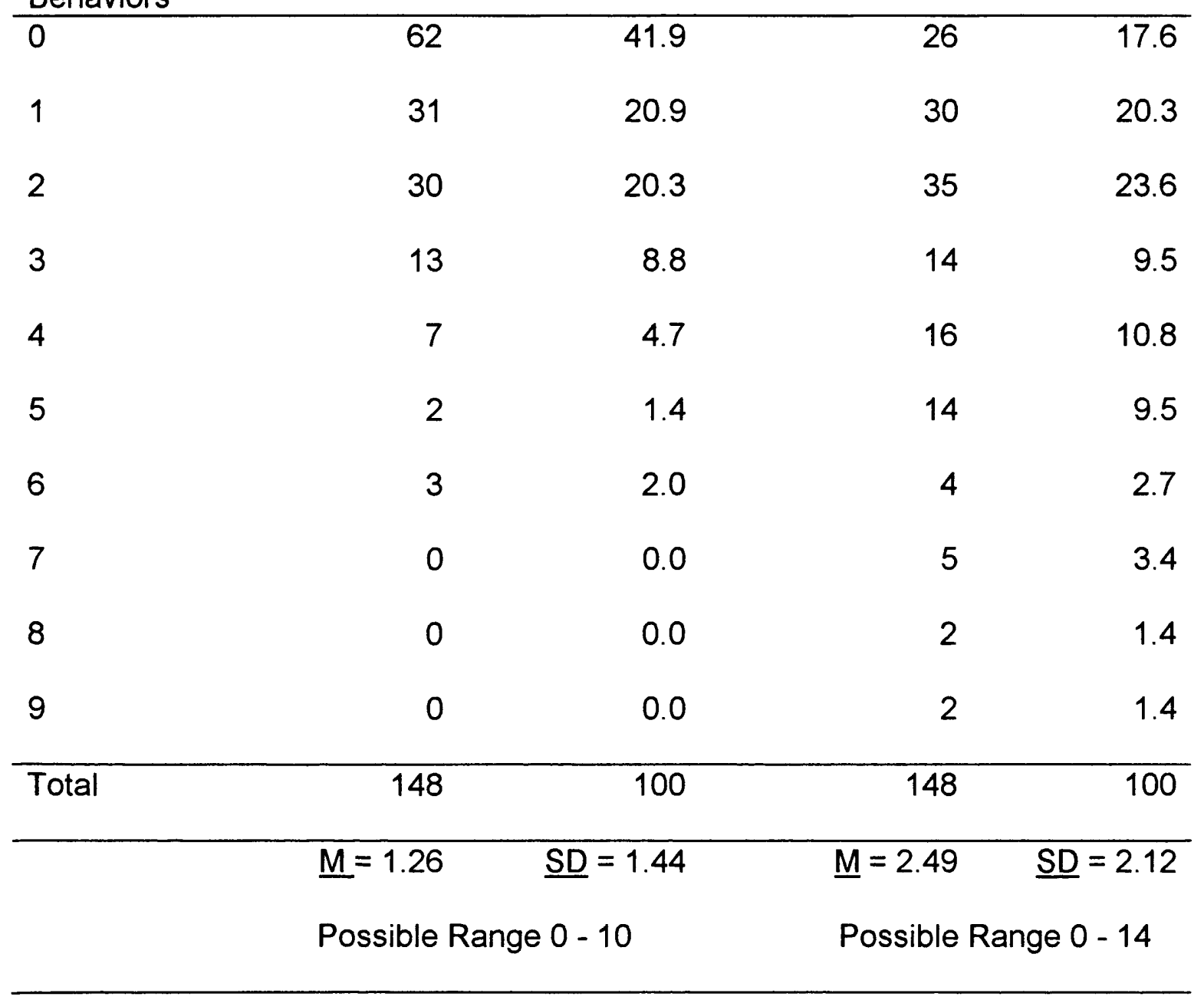

Clinical
Frequency Percent $\quad$ Frequency Percent

Percent 
unethical behaviors in the classroom setting.

In analyzing the use of unethical behaviors in the total student experience (possible number of behaviors was 24$)$, the mean was $3.75(\underline{S D}=3.00)$, with a range of zero to 12 (See Table 4). The total possible number of unethical behaviors which could be reported in the workplace was 16 . The range for this section was zero to 13 with a mean of $4.18(\underline{S D}=2.90)$. The percentage of participants who reported they did not use any unethical behaviors during their nursing student experience was $12 \%(n=17)$. The percentage of participants who did not use any unethical behaviors in the workplace was slightly lower at $8 \%$ $(\underline{n}=12)$. In comparing the reported use of unethical behaviors in the nursing student experience and the workplace, the findings were similar.

In summary for the first research question, participants reported use of unethical behaviors more frequently in the clinical setting than in the classroom. Frequency of reported use of unethical behaviors in the overall student experience was similar to use of unethical behaviors in the workplace.

The second research question examined the unethical behaviors which were most reported as used by the participants in the study. The top four behaviors reported used in the classroom were copying sentences from a reference without giving credit to the reference (46\%), use of references in the paper without listing them in the bibliography (30\%), permitting another student to copy from a paper (16\%), and working with another student on a paper 
Table 4

Frequency of Reported Use of Unethical Behaviors in the Overall Student

Experience and in the Workplace $(N=148)$

\section{Student Experience}

Number of

Frequency

Percent

Behaviors

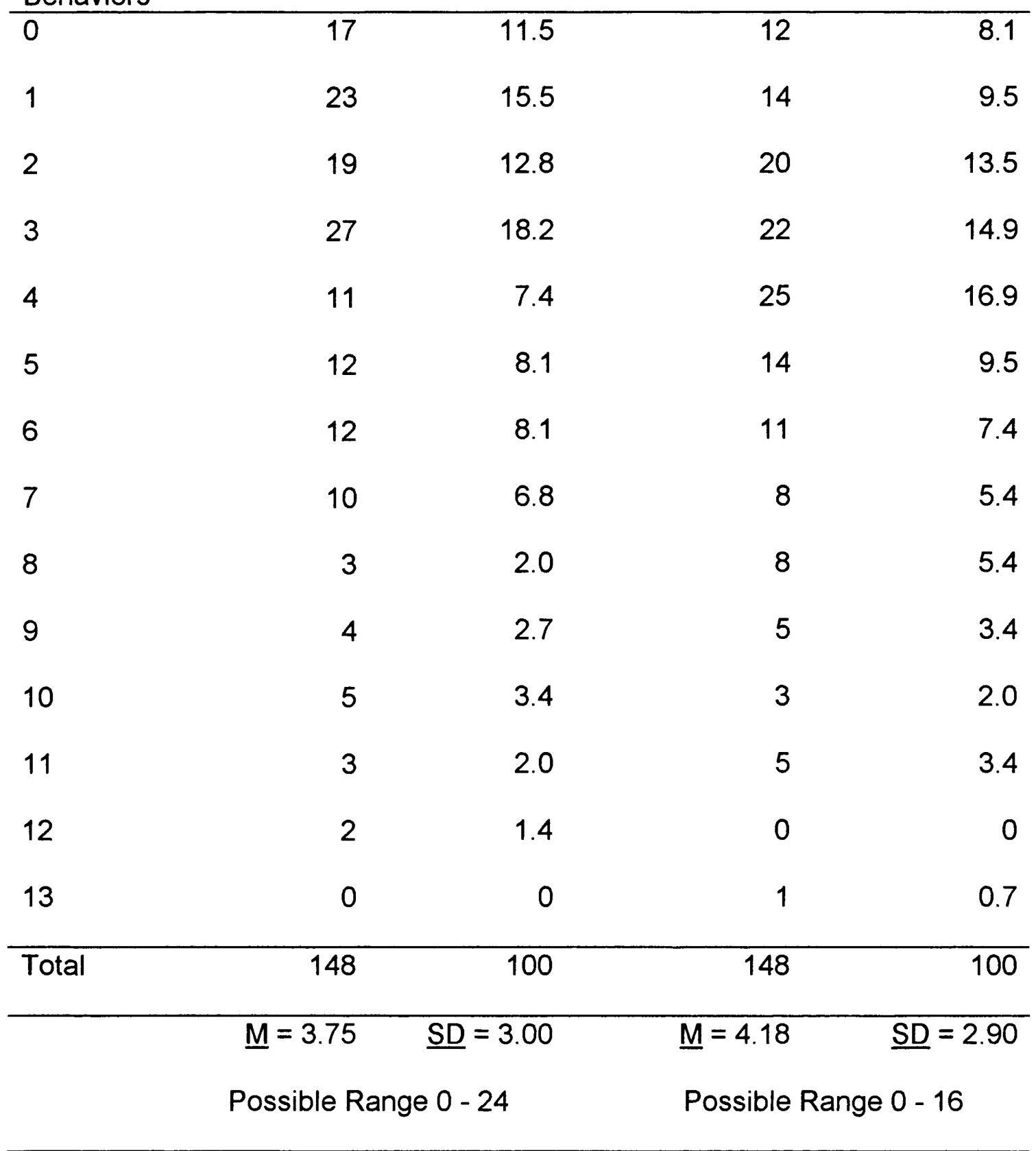

Workplace

Frequency Percent 
when it was not permitted by the instructor (14\%). Two behaviors tied for fifth, copying answers from another student's examination (7\%) and preparing an assignment for another student to submit as their own work (7\%). Table 5 list all behaviors reported used in this study as well as the assigned severity rating for each one. Severity ratings were assigned by nurse experts.

In the student clinical setting the most frequently utilized unethical behavior was talking about patients in the public areas of the hospital (46\%). Performing a procedure without adequate understanding of how to do it was the next most frequently utilized behavior (41\%). Participants reported that they gave a false reason for absences from clinical or class (35\%) as the next most frequently used behavior, followed by coming to the clinical area without being prepared for the assignment (32\%). The fifth most frequently used behavior related to breaking sterile technique and not correcting the error $(25 \%)$.

In the workplace, the most frequently reported behavior was giving a false reason for being absent from work (61\%), in comparison with only $35 \%$ of the participants utilizing this behavior as a nursing student. The second most frequently utilized behavior in the workplace was talking about patients in public areas of the hospital (41\%). This same behavior was the most frequently reported student clinical experience behavior. In the workplace, $39 \%$ of the participants reported that they photocopied personal papers at work, and $27 \%$ reported that they performed a procedure without adequate understanding of 
Table 5

Frequencies and Severity Rating for Self Report of Unethical Behavior Inventory

$\underline{(N=148)}$

\begin{tabular}{lclc}
\hline Behavior & $\begin{array}{c}\text { Severity } \\
\text { Rating }\end{array}$ & $\underline{\mathrm{n}}$ & $\%$ \\
\hline
\end{tabular}

Overall Student Experience - Classroom

Behaviors

allowed another student to copy from my

$5 \quad 24 \quad 16.2$

examination or test paper.

copied an answer from another student's

$5 \quad 10 \quad 6.8$

examination or quiz.

prepared an assignment for another student to

submit as their own work.

$\begin{array}{lll}5 & 10 & 6.8\end{array}$

turned in an assignment as my own when it

$\begin{array}{lll}5 & 4 & 2.7\end{array}$

was done by someone else.

used notes during an examination or quiz

when it was not permitted.

$\begin{array}{lll}5 & 3 & 2.0\end{array}$

asked another student to take an examination

5

$1 \quad 0.7$

for me.

copied a few sentences from a reference

$\begin{array}{lll}4 & 68 & 45.9\end{array}$

without giving credit to the reference.

used references for a paper that were not

$\begin{array}{lll}4 & 44 & 29.7\end{array}$

listed in the bibliography.

worked with another student on an assignment

$4 \quad 21 \quad 14.2$

when the instructor did not permit it.

Note: Severity Rating: $1=$ not unethical, $5=$ severely unethical

Note: continued on next page 
Table 5 (con't)

\begin{tabular}{llll}
\hline Behavior & $\begin{array}{l}\text { Severity } \\
\text { Rating }\end{array}$ & $\underline{\mathrm{n}}$ & $\%$ \\
\hline
\end{tabular}

Overall Student Experience - Clinical Behaviors

talked about patients in public areas of the

$5 \quad 68$

45.9 hospital.

performed a procedure without adequate understanding of how to do it.

$5 \quad 60 \quad 40.5$

broke sterile technique and did not correct the

5

$37 \quad 25.0$

contamination.

recorded vital signs when they were not taken

$5 \quad 22$

14.9

or precisely recalled.

took equipment from the hospital for personal

$5 \quad 20 \quad 13.5$ use.

took medications from the hospital for personal

$5 \quad 19$

12.8 use.

made an error that affected patient care.

$5 \quad 17 \quad 11.5$

recorded medications as given even though

$\begin{array}{lll}5 & 8 & 5.4\end{array}$

they were not given.

recorded that treatments or observations as

completed when they had not been done

5

8

5.4

went to the clinical area under the influence of

5

0

0

alcohol or drugs.

had another student perform my assignment

without the instructor's knowledge

5

4

2.7

Note: Severity Rating: 1 = not unethical, 5 = severely unethical

Note: continued on next page 
Table 5 (con't)

\begin{tabular}{|c|c|c|c|}
\hline Behavior & $\begin{array}{l}\text { Severity } \\
\text { Rating }\end{array}$ & $\underline{\mathrm{n}}$ & $\%$ \\
\hline $\begin{array}{l}\text { Overall Student Experience - Clinical Setting } \\
\text { gave a false reason for being absent from } \\
\text { clinical or class }\end{array}$ & 4 & 52 & 35.1 \\
\hline $\begin{array}{l}\text { came to the clinical area without being } \\
\text { prepared for the patient assignment }\end{array}$ & 4 & 47 & 31.8 \\
\hline \multicolumn{4}{|l|}{ Workplace Setting by Self } \\
\hline $\begin{array}{l}\text { talked about patients in public areas of the } \\
\text { hospital }\end{array}$ & 5 & 61 & 41.2 \\
\hline $\begin{array}{l}\text { performed a procedure without adequate } \\
\text { understanding of how to do it }\end{array}$ & 5 & 40 & 27.0 \\
\hline $\begin{array}{l}\text { took medications from the hospital for personal } \\
\text { use. }\end{array}$ & 5 & 38 & 25.7 \\
\hline $\begin{array}{l}\text { recorded vital signs when they were not taken } \\
\text { or precisely recalled. }\end{array}$ & 5 & 35 & 23.6 \\
\hline $\begin{array}{l}\text { broke sterile technique and did not correct the } \\
\text { contamination. }\end{array}$ & 5 & 34 & 23.0 \\
\hline took hospital equipment for personal use. & 5 & 30 & 20.3 \\
\hline omitted reporting the medication error. & 5 & 28 & 18.9 \\
\hline $\begin{array}{l}\text { recorded medications as given even though } \\
\text { they were not given. }\end{array}$ & 5 & 20 & 13.5 \\
\hline $\begin{array}{l}\text { recorded that treatments or observations as } \\
\text { completed when they had not been done. }\end{array}$ & 5 & 16 & 10.8 \\
\hline took credit for someone else's ideas or work. & 5 & 6 & 4.1 \\
\hline
\end{tabular}

Note: Severity Rating: $1=$ not unethical, $5=$ severely unethical Note: continued on next page 
Table 5 (con't)

Behavior

Severity

$\underline{\mathrm{n}}$

$\%$

Workplace Setting by Self

Rating

omitted reporting the incident involving a

5

6

4.1

patient or visitor.

went to the work under the influence of alcohol

or drugs.

5

0.0

0.0

gave a false reason for being absent from

4

88

59.5

work.

photocopied personal papers.

2

55

37.2

made a medication error.

1

111

75.0

was involved in an incident related to a patient

1

51

34.5 or visitor.

Workplace Setting by Peers

talked about patients in public areas of the

$5 \quad 103$

69.6

hospital

took credit for someone else's ideas or work.

$5 \quad 79$

53.4

took medications from the hospital for personal

5

73

49.3 use.

performed a procedure without adequate

5

73

49.3

understanding of how to do it

recorded that treatments or observations as

completed when they had not been done.

5

$69 \quad 46.6$

broke sterile technique and did not correct the

5

67 45.3 contamination.

Note: Severity Rating: 1 = not unethical, 5 = severely unethical

Note: continued on next page 
Table 5 (con't)

\begin{tabular}{|c|c|c|c|}
\hline Behavior & $\begin{array}{l}\text { Severity } \\
\text { Rating }\end{array}$ & $\underline{\mathrm{n}}$ & $\%$ \\
\hline \multicolumn{4}{|l|}{ Workplace Setting by Peers } \\
\hline $\begin{array}{l}\text { recorded vital signs when they were not taken } \\
\text { or precisely recalled. }\end{array}$ & 5 & 67 & 45.3 \\
\hline omitted reporting the medication error. & 5 & 65 & 43.9 \\
\hline took hospital equipment for personal use. & 5 & 61 & 41.2 \\
\hline $\begin{array}{l}\text { recorded medications as given even though } \\
\text { they were not given. }\end{array}$ & 5 & 56 & 37.8 \\
\hline $\begin{array}{l}\text { came to work under the influence of alcohol or } \\
\text { drugs. }\end{array}$ & 5 & 52 & 35.1 \\
\hline $\begin{array}{l}\text { omitted reporting the incident involving a } \\
\text { patient or visitor. }\end{array}$ & 5 & 41 & 27.7 \\
\hline $\begin{array}{l}\text { gave a false reason for being absent from } \\
\text { work. }\end{array}$ & 4 & 110 & 74.3 \\
\hline photocopied personal papers. & 2 & 62 & 41.9 \\
\hline made a medication error. & 1 & 119 & 80.4 \\
\hline $\begin{array}{l}\text { was involved in an incident related to a patient } \\
\text { or visitor. }\end{array}$ & 1 & 83 & 56.1 \\
\hline
\end{tabular}

Note: Severity Rating: $1=$ not unethical, $5=$ severely unethical 
how to do it. The fifth most frequently used unethical behavior in the workplace was taking medications for personal use (26\%). In comparison, only $13 \%$ reported utilizing this behavior as a nursing student. Although breaking sterile technique and not correcting the error was not one of the top five unethical behaviors in the workplace, it was the fifth most frequently utilized student clinical setting behavior. The percentage of use in the student clinical setting $(25 \%)$ was similar to the frequency of use in the workplace $(23 \%)$.

In summary for the second research question, the top three classroom setting unethical behaviors utilized related to falsifying papers. These behaviors included not giving credit for a reference, omitting a reference from the bibliography, or permitting another student to copy from an exam paper. Three of the same unethical behaviors were utilized most frequently in both the student clinical setting and in the workplace, although they did not occur in the same order. The three behaviors were talking about patients in the public areas of the hospital, performing a procedure without adequate understanding of how to do it, and giving a false reason for being absent.

Relationship of Use of Unethical Behaviors

The first hypothesis stated that the individual who participated in unethical behaviors in the classroom or clinical setting during their nursing student experience also engaged in unethical behaviors in the workplace as a registered nurse. In order to examine the relationship between percent use of unethical behaviors in the student experience and the workplace, a percentage of use was 
calculated. This percent use was also calculated for the classroom and student clinical settings. Using these percent use scores, correlation coefficients between all pairs of classroom setting, clinical setting, overall student experience, and workplace setting were then calculated (See Table 6).

The correlation coefficient for percent use of unethical behaviors in the overall student experience with workplace behaviors was $\underline{r}=.630$ and was statistically significant, $\underline{\mathrm{p}}<.001$. The higher the number of unethical behaviors used as a student, the higher the number used in the workplace. It should also be noted that a higher percentage of participants utilized unethical behaviors in the workplace $(\underline{M}=17.43 \%)$ than as a student $(\underline{M}=15.63 \%), \underline{t}(147)=2.07$, $\underline{p}=04$.

Correlation coefficients for each component of the student experience (classroom and clinical) with workplace behaviors were also calculated. The correlation between classroom behaviors and workplace behaviors was $\underline{r}=.373$, $\mathrm{p}<.001$. Nurses who participated in more unethical behaviors in the nursing student classroom also used more in the workplace. Although statistically significant, the correlation coefficient was less than the coefficient for overall student experience and the workplace, indicating a weaker relationship between the two settings of unethical behaviors. A higher percentage of nurses reported participating in unethical behaviors in the workplace $(M=17.43 \%)$ than as a student in the classroom setting $(\underline{M}=12.57 \%), \underline{t}(147)=3.96, \underline{p}<.001$. The 
Table 6

Mean, Standard Deviations and Correlation Between Percent Use of Unethical

Behaviors in the Workplace and Overall Student Experience, Classroom Setting and Clinical Settings. $(N=148)$

\begin{tabular}{lccc}
\hline Correlation of & $\begin{array}{c}\text { Overall Student } \\
\text { Percentage of Use with }\end{array}$ & $\begin{array}{c}\text { Classroom } \\
\text { Experience }\end{array}$ & $\begin{array}{c}\text { Clinical Setting } \\
\text { Workplace }\end{array}$ \\
& .630 & .373 & .639 \\
& $\mathrm{p}<.001$ & $\mathrm{p}<.001$ & $\mathrm{p}<.001$ \\
Classroom & & & .402 \\
& & $\mathrm{p}<.001$
\end{tabular}

\begin{tabular}{lcc}
\hline Variable & $\underline{M}$ & $\underline{\text { SD }}$ \\
\hline Overall Student Experience & 15.63 & 12.51 \\
Classroom Setting & 12.57 & 14.39 \\
Clinical Setting & 17.81 & 15.15 \\
Workplace & 17.43 & 12.06 \\
\hline
\end{tabular}


correlation coefficient between student clinical behaviors and workplace behaviors was $\underline{\mathrm{r}}=.639, \underline{\mathrm{p}}<.001$. Participants who reported use of a higher number of unethical behaviors in the student clinical experience also reported use of more unethical behaviors in the workplace. A similar percentage of participants used unethical behaviors in the student clinical experience $(\underline{M}=17.81 \%)$ and in the workplace $(\underline{M}=17.43 \%), \underline{t}(147)=0.39, \underline{p}=.67$. The correlation between the use of unethical behaviors in the classroom with the clinical setting was $\underline{r}=.402, \underline{p}<.001$. The higher the number of unethical behaviors utilized in the classroom setting, the higher the number utilized in the clinical setting. It should be noted that more unethical behaviors were utilized in the clinical setting $(\underline{M}=17.81 \%)$ than in the classroom $(\underline{M}=12.57 \%)$, $\mathrm{t}(147)=3.95, \underline{\mathrm{p}}<.001$.

The hypothesis that there was a relationship between the use of unethical behaviors in the student experience and their use in the workplace was confirmed. The higher the percentage use of unethical behaviors in the classroom setting, the student clinical experience or overall student experience, the higher the percentage use of unethical behaviors in the workplace.

\section{Severity of Unethical Behaviors Utilized}

The second hypothesis stated that there was a relationship between the severity of unethical behaviors utilized in the classroom or clinical setting and those in the workplace. Nurse experts rated each one of the behaviors using a scale of $1=$ not unethical to $5=$ severely unethical. The closest whole number to 
the mean, median and mode was assigned as the severity rating for each behavior. The severity rating for each unethical behavior was used to calculate a weighted score for overall student experience, classroom, clinical and workplace. These weighted scores were used to examine the relationship of severity of unethical behaviors utilized in the classroom, clinical and workplace settings. In addition, in order to analyze mean differences, a proportional adjustment was made in calculating these additional weighted scores because of differing number of behaviors in each section.

The correlation coefficient for weighted overall student experience with weighted workplace behaviors was $\underline{r}=.637, \underline{\mathrm{p}}<.001$ (See Table 7). Nurses who engaged in unethical behaviors considered more severe during the nursing student experience were more likely to use unethical behaviors considered more severe in the workplace. In addition, the mean for weighted unethical behaviors in the workplace $(\underline{M}=16.89)$ was higher than in the overall student experience (adjusted $\underline{M}=11.44) \underline{t}(147)=5.99, \underline{p}<.001$. Participants indicated that they used more severe unethical behaviors in the workplace than in their nursing student experience.

Weighted scores for each component of the nursing student experience (classroom setting, clinical setting) and the workplace were utilized to calculate correlation coefficients. Nurses who utilized more severe unethical behaviors in the classroom setting also used more severe unethical behaviors in the workplace $\underline{r}=.372, \underline{p}<.001$. Participants who reported classroom use of 
behaviors that were rated as more severely unethical were more likely to utilize the more severely unethical behaviors in the workplace. Although this was significant, the correlation coefficient was less than the coefficient calculated for the overall student experience with the workplace. There was a statistically significant difference between the means for these two areas $\underline{t}(147)=12.31$, $\underline{p}<.001$, with a classroom mean $(\underline{M}=5.35)$ lower than the workplace mean (adjusted $\underline{M}=10.55$ ). The participants utilized less severely unethical behaviors in the classroom than in the workplace. The correlation coefficient using the weighted clinical score and the workplace was $\underline{r}=.633, \underline{p}<.001$. Nurses who utilized more severely unethical behaviors in the student clinical setting were more likely to use more severely unethical behaviors in the workplace. In addition, participants indicated use of more severely unethical behaviors in the workplace $(\underline{M}=16.89)$ than in the student clinical setting (adjusted $\underline{M}=10.64$ ), $\underline{t}(143)=7.38, \underline{p}<.001$. The correlation coefficient between the weighted classroom score and the clinical score was $\underline{r}=.407, \underline{p}<.001$. Participants who used behaviors rated as more severely unethical in the classroom were more likely to use more severely unethical behaviors in the student clinical experience. Participants indicated use of more severely unethical behaviors in the student clinical setting (adjusted $\underline{M}=8.68$ ) than in the classroom $(\underline{M}=5.35$ ), $\underline{t}(143)=-10.22, \underline{p}<.001$.

The hypothesis that there was a relationship between the severity of unethical behaviors utilized in the classroom or student clinical setting with those 
Table 7

Means, Standard Deviations and Correlation Coefficients Between Weighted

Scores for Unethical Behaviors in the Workplace, and Overall Student

Experience, Classroom Setting, and Clinical Setting. $(N=148)$

\begin{tabular}{lrrr}
\hline $\begin{array}{l}\text { Correlation of Weighted } \\
\text { Scores with }\end{array}$ & $\begin{array}{r}\text { Overall Student } \\
\text { Experience }\end{array}$ & $\begin{array}{r}\text { Classroom } \\
\text { Setting }\end{array}$ & $\begin{array}{r}\text { Clinical } \\
\text { Setting }\end{array}$ \\
\hline Workplace & .637 & .372 & .633 \\
& $p<.001$ & $p<.001$ & $p<.001$ \\
Classroom & & & .407 \\
& & & $p<.001$ \\
Variable & Range & Weighted Mean & \\
\hline Overall Student Experience & $0-24$ & 17.15 & 13.92 \\
Classroom Setting & $0-10$ & 5.35 & 6.32 \\
Clinical Setting & $0-14$ & 11.58 & 10.00 \\
Workplace & $0-16$ & 16.89 & 14.34
\end{tabular}


in the workplace was confirmed. Participants who used more severely unethical behaviors in the classroom, clinical setting, or overall student experience were more likely to use more severely unethical behaviors in the workplace. The correlations were large between the use of severely unethical behaviors in the overall student experience and the workplace, and also between the student clinical setting and the workplace. The correlation was smaller between use of severely unethical behaviors between the classroom setting and the clinical setting and also between the classroom setting and the workplace. These results are similar to percentage of usage of unethical behaviors in the first hypothesis.

\section{Years of Practice and Use of Unethical Behaviors}

Another research question examined the relationship between the number of years of nursing practice and the frequency of participation in unethical behaviors in the workplace. A correlation coefficient was calculated between the actual number of years of practice and the percentage of use of unethical behaviors in the workplace (See Table 8). The relationship was not significant, $\underline{\text { }}$ $=.055, \underline{p}=.509$. Correlation coefficients were also calculated for number of years and the overall student experience, classroom and clinical settings. The number of years of practice was not correlated with the percentage of use in any of these three settings. But there is a suggested difference that those with more years of practice used less unethical behaviors in the classroom, marginally significant, $\underline{p}<.10$. No relationship was found between

Table 8 
Correlation of Years of Practice with Percentage of Use of Unethical Behaviors

in Overall Student Experience, Classroom Setting. Clinical Setting, and

Workplace

\begin{tabular}{lrrrr}
\hline $\begin{array}{l}\text { Correlation of } \\
\begin{array}{l}\text { Percentage of Use } \\
\text { with }\end{array}\end{array}$ & $\begin{array}{c}\text { Overall } \\
\text { Student } \\
\text { Experience }\end{array}$ & $\begin{array}{c}\text { Classroom } \\
\text { Setting }\end{array}$ & $\begin{array}{l}\text { Clinical } \\
\text { Setting }\end{array}$ & Workplace \\
\hline Years of Practice & -.084 & -.1520 & -.015 & .055 \\
& $p=.313$ & $p=.067$ & $p=.860$ & $p=.509$ \\
\hline
\end{tabular}


number of years of practice and use of unethical behaviors in the overall student experience, classroom setting, clinical setting or workplace.

Type of Initial Nursing Education and Use of Unethical Behaviors

The relationship between the initial type of nursing education and the use of unethical behaviors was also examined. One way analysis of variance (ANOVA) was used to make comparisons among groups. The percent use of unethical behaviors in each setting (overall student experience, classroom setting, clinical setting and workplace) were compared by type of initial nursing education (associate degree [ADN], diploma, and baccalaureate [BSN]) (See Table 9). The groups were not significantly different at the .05 level on any of the percentage of use variables. No graduates of any one type of initial nursing education demonstrated more frequent use of unethical behaviors. Therefore no relationship between type of initial nursing education and use of unethical behaviors was demonstrated.

Participation in Unethical Behaviors and Being Raised Inside or Outside the $\underline{\text { United States }}$

Another research question examined if there was a relationship between the percent use of unethical behaviors and being raised inside or outside the United States. Participants were asked to indicate whether they spent the majority of time from birth to age 18 inside or outside the United States or divided approximately equally between the two countries. Only two participants indicated that they spent the majority of time divided between the two countries. 
Table 9

Means, Standard Deviations for Percent Use of Unethical Behaviors by Type of

Initial Nursing Education ( $N=148$ )

\begin{tabular}{|c|c|c|c|c|c|}
\hline Variable & $\begin{array}{c}\text { ADN } \\
(n=80)\end{array}$ & $\begin{array}{l}\text { Diploma } \\
(\mathrm{n}=32)\end{array}$ & $\begin{array}{c}\mathrm{BSN} \\
(\mathrm{n}=31)\end{array}$ & F Ratio & p value \\
\hline $\begin{array}{l}\text { Overall Student } \\
\text { Experience }\end{array}$ & $\begin{array}{r}15.83 \\
(11.76)\end{array}$ & $\begin{array}{r}14.71 \\
(13.47)\end{array}$ & $\begin{array}{r}17.88 \\
(13.66)\end{array}$ & 0.519 & 0.596 \\
\hline $\begin{array}{l}\text { Classroom } \\
\text { Setting }\end{array}$ & $\begin{array}{r}12.63 \\
(14.03)\end{array}$ & $\begin{array}{r}10.31 \\
(12.31)\end{array}$ & $\begin{array}{r}16.13 \\
(17.26)\end{array}$ & 1.030 & 0.275 \\
\hline Clinical Setting & $\begin{array}{r}18.13 \\
(14.28)\end{array}$ & $\begin{array}{r}17.86 \\
(16.92)\end{array}$ & $\begin{array}{r}19.12 \\
(16.01)\end{array}$ & 0.064 & 0.938 \\
\hline Workplace & $\begin{array}{r}19.21 \\
(12.34)\end{array}$ & $\begin{array}{r}16.01 \\
(11.31)\end{array}$ & $\begin{array}{r}16.13 \\
(11.82)\end{array}$ & 1.210 & 0.301 \\
\hline
\end{tabular}


Since this number was small, this category was not used in analysis of data for this question. Independent $\underline{t}$ tests were used to analyze the data for two groups, being raised inside the United States or being raised outside the United States (See Table 10). Percent use of unethical behaviors in each one of the four settings, overall student experience, classroom setting, clinical setting and workplace was analyzed. No significant difference between groups was noted for any of the percent use variables, indicating that the participants' use of unethical behaviors did not vary according to whether they were raised inside or outside the United States.

\section{Frequency of Use of Unethical Behaviors By Peers}

The last research question examined the frequency of participation in unethical behaviors by registered nurses as reported by their peers. The last section of the questionnaire asked the participants to indicate if they knew if other nurses utilized any of the unethical behaviors. Only $4 \%(\underline{n}=6)$ reported that their peers did not use any unethical behaviors (See Table 11). In comparison, $12 \%(\underline{n}=17)$ reported that they themselves did not use any unethical behaviors during their student experience, and $8 \%(\underline{n}=12$ had not used any in the workplace.

The range of use of unethical behaviors by registered nurse as reported by their peers was 0 to 16 with a mean of 7.97 . The range of use of unethical behaviors by participants was 0 to 13 with a mean of 4.18 . The total number of behaviors for both sections was 16 . Thirty-eight percent of participants $(\underline{n}=56)$ 
Table 10

Means, Standard Deviations and $t$ tests for Percent Use of Unethical Behaviors in Four Settings by Whether Participants Were Raised Inside or Outside the United States $(N=148)$

\begin{tabular}{|c|c|c|c|c|c|c|}
\hline \multirow[b]{2}{*}{ Variable } & \multicolumn{2}{|c|}{$\begin{array}{c}\text { Inside US } \\
(n=90)\end{array}$} & \multicolumn{2}{|c|}{$\begin{array}{l}\text { Outside US } \\
(\underline{n}=54)\end{array}$} & \multirow[b]{2}{*}{$\underline{t}$} & \multirow[b]{2}{*}{$\underset{\text { value }}{\underline{p}}$} \\
\hline & $\underline{M}$ & $\underline{\mathrm{SD}}$ & $\underline{M}$ & $\underline{\mathrm{SD}}$ & & \\
\hline $\begin{array}{l}\text { Overall Student } \\
\text { Experience }\end{array}$ & 15.28 & 11.16 & 16.59 & 14.76 & -0.60 & .547 \\
\hline Classroom & 11.78 & 13.73 & 13.89 & 16.30 & -0.84 & .400 \\
\hline Clinical & 17.78 & 14.65 & 18.52 & 16.10 & -0.28 & .778 \\
\hline Workplace & 16.76 & 11.09 & 18.83 & 13.75 & -0.99 & .324 \\
\hline
\end{tabular}


reported that they used between one and three behaviors. Only $17 \%(\underline{n}=24)$ reported that their peers used between one and three unethical behaviors. Only one participant $(1 \%)$ reported that they used more than 11 unethical behaviors. In comparison, 38 participants (26\%) reported their peers' use of more than 11 unethical behaviors.

A correlation coefficient was calculated to determine if a relationship existed between percent use of unethical behaviors in the workplace and the reported use of unethical behaviors by peers. Nurses who utilized unethical behaviors in the workplace were more likely to report use of unethical behaviors by their peers $\underline{r}=.504, \underline{p}<.001$. Participants reported more use of unethical behaviors by peers $(\underline{M}=33.22 \%)$ than they used themselves $(\underline{M}=17.43 \%) \underline{t}$ $(147)=-11.37, \underline{p}<.001$

In summary, nurses who used unethical behaviors themselves were more likely to report use of unethical behaviors by their peers. Participants reported use of more unethical behaviors by their peers than they themselves used.

\section{Additional Findings}

One way ANOVA was used to analyze differences among participants enrolled in public and private institutions at the undergraduate and graduate level on percent use of unethical behaviors in all settings. A significant difference was found for percent use in the classroom setting, $E(3,144)=3.36$, $\underline{p}=.02$ (See Table 12). Tukey's post hoc test was used to further analyze differences among groups, $\underline{p}<.05$. Participants who were enrolled in private 
Table 11

Frequency of Participation in Unethical Behaviors in the Workplace as Reported for Themselves and for Peers (Possible Range 0 - 16)

\begin{tabular}{|c|c|c|c|c|}
\hline \multirow{2}{*}{$\begin{array}{l}\text { Number } \\
\text { of Behaviors }\end{array}$} & \multicolumn{2}{|c|}{ Own Use } & \multicolumn{2}{|c|}{ Peer Use } \\
\hline & $n$ & $\%$ & $n$ & $\%$ \\
\hline 0 & 12 & 8.1 & 6 & 4.1 \\
\hline 1 & 14 & 9.5 & 4 & 2.7 \\
\hline 2 & 20 & 13.5 & 6 & 4.1 \\
\hline 3 & 22 & 14.9 & 15 & 10.1 \\
\hline 4 & 25 & 16.9 & 11 & 7.4 \\
\hline 5 & 14 & 9.5 & 10 & 6.8 \\
\hline 6 & 11 & 7.4 & 14 & 9.5 \\
\hline 7 & 8 & 5.4 & 9 & 6.1 \\
\hline 8 & 8 & 5.4 & 5 & 3.4 \\
\hline 9 & 5 & 3.4 & 11 & 7.4 \\
\hline 10 & 3 & 2.0 & 11 & 7.4 \\
\hline 11 & 5 & 3.4 & 8 & 5.4 \\
\hline 12 & 0 & 0 & 5 & 3.4 \\
\hline 13 & 1 & 0.7 & 9 & 6.1 \\
\hline 14 & 0 & 0 & 5 & 3.4 \\
\hline 15 & 0 & 0 & 10 & 6.8 \\
\hline 16 & 0 & 0 & 9 & 6.1 \\
\hline \multirow[t]{2}{*}{ Total } & 148 & 100 & 148 & 100 \\
\hline & $\underline{M}=4.18$ & $\underline{\mathrm{SD}}=2.90$ & $\underline{M}=7.97$ & $\underline{\mathrm{SD}}=4.65$ \\
\hline
\end{tabular}


undergraduate courses reported use of fewer unethical behaviors in the classroom ( $\underline{M}=0.734, \underline{S D}=1.03$ ) than those enrolled in public undergraduate courses $(\underline{M}=1.83, \underline{S D}=1.87)$. No difference in percent use of unethical behaviors in the other settings were found among participants enrolled in graduate courses.

Further comparisons were made for individual items that were similar for the student clinical experience and the workplace. McNemar's or Binomial Tests were used to analyze reported use of the same behavior in the clinical experience and the workplace for matched items. For instance, if a participant indicated that they talked about patients in public areas as a student, did that same individual also report they used that behavior in the workplace? Behaviors which participants used in both the clinical and workplace settings included breaking sterile technique and not correcting the contamination, $p=.66$, talking about patients in public areas, $\mathrm{p}=.28$, and recording treatments that were not done as completed, $\underline{p}=.10$. Having another student complete a clinical assignment was matched with taking credit for another's work as a registered nurse and was found not to be statistically significant, $p=.73$.

Several behaviors were noted to be statistically significant using McNemar's or Binomial Tests, indicating the individual's behavior was different in the student clinical setting than in the workplace. Thirty-two percent of participants gave a false reason for being absent from the workplace, but did not give one as a student. Only $6 \%$ gave a false reason for being absent as a 
Table 12

Means and Standard Deviations for Use of Unethical Behaviors by Type of

Current Enrollment $(\mathrm{N}=148)$

\begin{tabular}{|c|c|c|c|c|c|c|}
\hline Variable & $\begin{array}{c}\text { Undergrad } \\
\text { Public } \\
(n=35)\end{array}$ & $\begin{array}{c}\text { Undergrad } \\
\text { Private } \\
(n=37)\end{array}$ & $\begin{array}{c}\text { Graduate } \\
\text { Public } \\
(\mathrm{n}=38)\end{array}$ & $\begin{array}{c}\text { Graduate } \\
\text { Private } \\
(n=38)\end{array}$ & $\mathrm{F}$ & $\mathrm{p}$ \\
\hline $\begin{array}{l}\text { Overall } \\
\text { Student } \\
\text { Experience }\end{array}$ & $\begin{array}{r}4.63 \\
(2.99)\end{array}$ & $\begin{array}{r}2.95 \\
(3.11)\end{array}$ & $\begin{array}{r}3.89 \\
(2.87)\end{array}$ & $\begin{array}{r}3.58 \\
(2.92)\end{array}$ & 1.99 & .118 \\
\hline Classroom & $\begin{array}{r}1.83 \\
(1.87)\end{array}$ & $\begin{array}{r}0.734 \\
(1.03)\end{array}$ & $\begin{array}{r}1.26 \\
(1.18)\end{array}$ & $\begin{array}{r}1.18 \\
(1.43)\end{array}$ & 3.36 & .020 \\
\hline Clinical & $\begin{array}{r}2.80 \\
(1.89)\end{array}$ & $\begin{array}{r}2.16 \\
(2.38)\end{array}$ & $\begin{array}{r}2.63 \\
(2.16)\end{array}$ & $\begin{array}{r}2.39 \\
(2.05)\end{array}$ & .621 & .602 \\
\hline Workplace & $\begin{array}{r}4.23 \\
(3.20)\end{array}$ & $\begin{array}{r}4.32 \\
(3.11)\end{array}$ & $\begin{array}{r}4.42 \\
(2.74)\end{array}$ & $\begin{array}{r}3.76 \\
(2.59)\end{array}$ & .3794 & .768 \\
\hline
\end{tabular}


student and not in the workplace, $\underline{x}^{2}(1)=23.56, \underline{p}<.001$ (See Table 13). Medications were taken for personal use by $10 \%$ of the individuals in the workplace but not in the student clinical setting, while only $3 \%$ indicated they took medications in the student clinical setting but not in the workplace, $\underline{x}^{2}(1)=$ 11.16, $\underline{p}<.001$. Ten percent of participants reported recording medications as given when they were not in the workplace but not as a student. Only $1 \%$ reported this behavior as a student but not in the workplace Binomial $\underline{p}=.42$. Additionally, $14 \%$ of participants reported that they recorded vitals signs that were not done or not correctly recalled in the workplace but not in the student clinical setting, $5 \%$ reported using this same behavior as a student but not as a registered nurse $\underline{X}^{2}(1)=4.97, \underline{p}<.03$. Ten percent of participants took equipment for personal use as a registered nurse but not as a student. In contrast, only $3 \%$ took equipment as a student but not as a registered nurse, Binomial $\mathrm{p}=.03$. Finally, $19 \%$ of the participants reported that they did a procedure without adequate knowledge in the student clinical setting, but not in the workplace, however, only $5 \%$ indicated they had done procedures without knowledge in the workplace but not as a student $X^{2}(1)=10.03, \underline{p}=.002$.

In summary, participants used some behaviors both as students and in the workplace, including talking about patients in public areas, recording treatments as done when they were not, and breaking sterile technique and not correcting it. Participants did change some behaviors from the student clinical setting to the workplace. More participants gave false reasons for absences, 
Table 13

Differences in Percent Use of Unethical Behaviors In Student Clinical Setting and the Workplace for Matched Items

\begin{tabular}{|c|c|c|c|c|c|c|}
\hline \multirow[b]{2}{*}{ Item } & \multicolumn{2}{|c|}{$\begin{array}{l}\text { Used in } \\
\text { Workplace } \\
\text { Not as } \\
\text { Student }\end{array}$} & \multicolumn{2}{|c|}{$\begin{array}{l}\text { Used as } \\
\text { Student not in } \\
\text { Workplace }\end{array}$} & \multirow[b]{2}{*}{$x^{2}$} & \multirow[b]{2}{*}{$\mathrm{p}$} \\
\hline & n & $\%$ & $\underline{n}$ & $\%$ & & \\
\hline $\begin{array}{l}\text { Gave false reason for } \\
\text { absence }\end{array}$ & 46 & 32 & 9 & 4 & 23.56 & $<.001$ \\
\hline $\begin{array}{l}\text { Took medications for } \\
\text { personal use }\end{array}$ & 22 & 15 & 4 & 3 & 11.12 & $<.001$ \\
\hline $\begin{array}{l}\text { Reported medications } \\
\text { as given when they } \\
\text { were not }\end{array}$ & 14 & 10 & 2 & 1 & -- & .004 \\
\hline $\begin{array}{l}\text { Took equipment for } \\
\text { personal use }\end{array}$ & 14 & 10 & 4 & 3 & -- & .03 \\
\hline $\begin{array}{l}\text { Recorded vital signs } \\
\text { when not taken }\end{array}$ & 21 & 14 & 8 & 5 & 4.97 & .03 \\
\hline $\begin{array}{l}\text { Did procedures } \\
\text { without adequate } \\
\text { knowledge }\end{array}$ & 8 & 5 & 28 & 19 & 10.03 & .002 \\
\hline
\end{tabular}

Note. Binomial tests were done for small samples. 
took medications or equipment for personal use, recorded medications that were not given and recorded vital signs that were not taken in the workplace than they did as students. More participants reported that they did procedures without adequate knowledge as students than in the workplace.

\section{Summary}

This study examined use of unethical behaviors in the nursing student experience and in the workplace by registered nurses. Two hypotheses and six research questions were explored. This chapter analyzed data in relation to these hypotheses and research questions.

The first hypothesis stated that the individual who participated in unethical behaviors during their nursing student experience also engaged in unethical behaviors in the workplace as a registered nurse. Correlation coefficients were used to compare use of unethical behaviors in each of the three settings, classroom, clinical, and overall student experience, with use of unethical behaviors in the workplace. Positive correlations were found between all three areas and the workplace. The hypothesis was confirmed. There was a relationship between use of unethical behaviors in the student experience and in the workplace.

The second hypothesis examined the relationship between the severity of unethical behaviors utilized in the student experience with those used in the workplace. There were positive relationships between the severity of unethical behaviors used during the overall student experience, the classroom setting and 
the student clinical setting with the severity of unethical behaviors used in the workplace. The hypothesis was confirmed.

Participants reported use of unethical behaviors more frequently in the clinical setting than in the classroom. Use of unethical behaviors in the overall student experience was similar to the use of unethical behaviors in the workplace. Additionally, three of the same unethical behaviors, talking about patients in public areas of the hospital, performing procedures without adequate knowledge and giving false reasons for absences, were used most frequently in both the clinical setting and in the workplace.

One way ANOVAs, $\underline{t}$ and correlational tests were used to analyze the relationship between demographic variables and percent use of unethical behaviors in the nursing student experience or the workplace. No relationships were found between the number of years of practice, the type of initial education, or whether an individual was raised inside or outside the United States and the percent use of unethical behaviors in any setting.

In addition, one way ANOVAs were used to analyze differences among the participants by type of current enrollment. Participants enrolled in private undergraduate courses reported less use of unethical behaviors in the classroom during their initial nursing education than those enrolled in private undergraduate courses.

Matched items were analyzed to see if use of specific unethical behaviors differed from the student clinical experience and in the workplace. Participants 
used the following behaviors more in the workplace than as students, giving a false reason for absence, taking medications or equipment for personal use, recording medications that were not given, and recording vital signs that were not done or precisely recalled. Participants reported that they did procedures without adequate knowledge more in the student clinical setting than they did in the workplace. 


\section{CHAPTER V}

\section{Discussion}

This study was conducted in order to examine the relationship between use of unethical behaviors by nursing students and use by registered nurses in the workplace. A questionnaire was completed by registered nurses who were enrolled in undergraduate and graduate classes during the summer of 1997. They were asked to indicate any unethical behavior that they had engaged in during their initial nursing student experience, and in the workplace since they had become registered nurses. In addition, they were asked to indicate if they were aware of other nurses who had utilized these same unethical behaviors. Discussion of Results

There were two hypotheses and six research questions in this study. The first hypothesis stated that individuals who participated in unethical behaviors during their nursing school experience also engaged in unethical behaviors in the workplace as registered nurses. There was a statistically significant correlation between participation in unethical behaviors during the nursing student experience and participation in the workplace. This relationship existed for all three settings within the nursing student experience, the overall student experience, the classroom setting, and the student clinical setting. The correlation between use of unethical behaviors in the classroom and use in the clinical setting was not as strong as the correlations between clinical and workplace or overall student experience and workplace. There was also a 
correlation between use of unethical behaviors in the classroom setting and use of unethical behaviors in the clinical setting. Again, this correlation was not as strong as the correlations between the clinical setting and the workplace or the overall student experience and the workplace. It should also be noted that a higher percentage of unethical behaviors were used in the workplace than in the overall student experience or in the classroom setting. The percent use of unethical behaviors in the student clinical experience and the use of unethical behaviors in the workplace was similar. The types of behaviors which were used in the clinical and workplace setting, both ethical and unethical, were comparable. This may account for the closeness in the percent use of unethical behaviors in the student clinical setting and the workplace.

The individual who uses unethical behaviors in nursing school is more likely to use unethical behaviors in the workplace. The student who uses unethical behaviors in either the classroom or clinical setting is likely to use unethical behaviors in the workplace. However, there is a stronger correlation between use of unethical behaviors in the clinical setting than in the classroom. The individual who uses unethical behaviors in the classroom is more likely to use unethical behaviors in the clinical setting then the individual who does not use any unethical behaviors in the classroom.

The correlation between nursing student's use of unethical behaviors in the classroom and use in the clinical setting supports the work of Hilbert (1985, 1987). It also supports the work of Sierles, Hendrickx and Circle (1980) who 
reported a positive correlation between medical students' use of unethical behaviors in the classroom and clinical setting.

The second hypothesis stated that a relationship existed between the severity of unethical behaviors used in the classroom or clinical setting and use of unethical behaviors in the workplace. This hypothesis was confirmed. The use of more severely unethical behaviors in the overall nursing student experience, the classroom setting or the student clinical setting were positively correlated with use of more severely unethical behaviors in the workplace. These findings are similar to those of Sims (1993), who reported a correlation between the severity of use of unethical classroom behaviors and unethical workplace behaviors in business students. There was also a positive correlation between the severity of unethical behaviors used in the classroom and those used in the clinical setting. The stronger correlations occurred between the overall student experience and the workplace and also between the student clinical experience and the workplace. Thus, the individual who used more severe unethical behaviors during nursing school is more likely to use severe unethical behaviors in the workplace than the individual who used less severe unethical behaviors in nursing school.

The frequency of use of unethical behaviors in the nursing student experience was $89 \%$. This finding is similar to the results of studies done by Baird (1980) and Sims (1993). The frequency of use of unethical behaviors in 
the workplace in this study was $92 \%$ which was lower than the results by Sims (98\%).

Three of the same unethical behaviors were used most frequently by participants in both the student clinical experience and in the workplace. These included talking about patients in public areas of the hospital, performing a procedure without adequate understanding of how to do it, and giving a false reason for being absent from work. Two of these behaviors, giving a false reason for absences and talking about patients in public areas of the hospital, were also in the top five behaviors in Hilbert's studies $(1985,1987)$. Some of the frequently used behaviors are alarming. These include breaking sterile technique without correcting the contamination, doing procedures without understanding, recording medications or treatments as done when they were not and failing to report medication errors. These behaviors have direct negative impact on client care.

Research questions examined the relationship between demographic variables and use of unethical behavior in the nursing student experience or the workplace. The demographic variables used in this study included years of practice, whether an individual was raised from birth to age 18 inside or outside the United States and thirdly, the type of initial nursing education. No statistically significant relationship was found between any of these three demographic data and the use of unethical behaviors in the nursing student experience or the workplace. It was found that participants who were enrolled in a public institution 
undergraduate program were more likely to have used unethical behaviors in the classroom during their initial nursing education than participants who were enrolled in a private undergraduate program. The participants who were enrolled in the private undergraduate courses also had more years of experience than those in the public courses.

Matched items for clinical and workplace behaviors were analyzed. The use of many of these items was found to be similar in both settings. There was no difference in the frequency by which participants reported that they talked about patients in public areas of the hospital, broke sterile technique and did not correct the error, and recorded treatments that were not done in both the student clinical experience and in the workplace. Participants reported that they gave a false reason for absence, took medications for personal use, recorded medications as given when they were not, recorded vital signs when they were not taken, and took equipment more in the workplace setting than they had as students in the clinical setting. Conversely, they reported they did procedures without adequate knowledge more in the student clinical setting than in the workplace.

\section{Conclusions}

The results of this study and an analysis of the literature indicated that an individual who used unethical behaviors in one setting is more likely to use unethical behaviors in another setting. In this study, nursing students who reported use of unethical behaviors, whether in classroom or in clinical, were 
likely to use unethical behaviors when they became registered nurses. Hilbert $(1985,1987)$ found a correlation between nursing students' use of unethical behaviors between the classroom and clinical settings. Correlation of use of unethical behaviors in different settings was found also in medical students (Sierles, Hendrickx \& Circle, 1980) and in business students (Sims, 1993).

Consistent with the correlation of use of unethical behaviors in different settings is the severity of use between settings. The results of this study indicated that the participant who used more severely unethical behaviors in nursing school, the more likely that individual was to use more severely unethical behaviors in the workplace. Sims (1993) reported this same relationship in use of severity of unethical behaviors in the business students.

Participants who were enrolled in public undergraduate courses reported a higher use of unethical behaviors in the classroom setting of their initial nursing education. The participants enrolled in the private undergraduate courses also had more years of practice that the other groups. One explanation for this difference may be that they may not remember what they did in the classroom as those who graduated more recently. No relationship was found between any other demographic variables and the use of unethical behaviors in the nursing student experience and the workplace. The other demographic variables studied included being raised inside or outside the United States, years of practice or type of initial nursing education. Reports of the relationship of demographic variables to use of unethical behaviors vary in the literature. 
Hilbert $(1985,1987)$ reported no relationship between age, sex or ethnic background and the use of unethical behaviors.

Participants reported a higher use of unethical behaviors by their peers in the workplace than they themselves used. It seems reasonable that it is easier to report behaviors in others than for oneself. Individuals tend to underreport their own use of unethical behaviors (Hilbert, 1985).

Several matched items between the behaviors used in the student clinical setting and in the workplace were studied. Since a positive relationship was found between use of unethical behaviors in these two settings, it was anticipated that some behaviors were used equally in both settings. Behaviors which were used equally in the clinical setting and the workplace included talking about patients in public areas of the hospital, breaking sterile technique and not correcting the contamination, recording treatments as done when they were not, and taking credit for another's work. Several behaviors were reported to have been used more in the workplace than in the clinical setting. These included giving a false reason for absence, taking medications or equipment for personal use, recording medications as given when they were not, and recording vital signs inaccurately. The nursing student clinical experience is usually closely supervised by an instructor. One explanation for this difference may be that the registered nurse had more opportunity to engage in these behaviors in the workplace than existed in the student clinical experience. Participants reported that they use the behavior of doing procedures without adequate 
understanding more frequently in the clinical experience than in the workplace. During the clinical experience, the student often does procedures with the instructor guiding them, and may not have felt that they had adequate knowledge of the procedure. Secondly, the student may not have wanted to indicate to the instructor that they did not know how to do a procedure for fear of receiving an unsatisfactory grade.

Recommendations

The results of this study indicated that there was a positive relationship between the use of unethical behaviors during the nursing student experience and the use of unethical behaviors in the workplace. This has implications that reach beyond the student experience into the health care system. Client's health may be at risk because the use of unethical behaviors. There are several implications for practice related to these findings, both for nursing faculty and nursing administrators.

Faculty have a great responsibility in promoting the moral growth of nursing students. First, they need to be able to assess the moral development of students. Learning activities that enhance moral development need to be planned and occur throughout the curriculum. Faculty need to develop their skills and knowledge base in teaching ethics (Hoyer, Booth, Spelman \& Richardson, 1991).

In addition, nursing faculty need to assess their own beliefs about what is ethical and unethical behaviors, and then discuss with these beliefs with each 
other. A definition of what are and are not acceptable behaviors by nursing students should be developed, as well as the consequences for using unethical behaviors. These should be clearly communicated to students. Faculty will also need the support and guidance of their deans. Additionally, a workshop on confronting unethical behaviors may enhance their ability to confront unethical behaviors. Included in this workshop should be issues related to due process for students.

Each faculty member should review what constitutes cheating, plagiarism and other unethical behaviors at the beginning of each theory course. The effect that use of unethical behaviors has on client care should be discussed both in theory and clinical courses. Faculty should role model ethical behaviors. If faculty seem unconcerned about unethical behaviors, the message is sent to students that they too need not be concerned about these issues.

Finally, faculty members should be aware that the student who uses unethical behaviors in the classroom is likely to use unethical behaviors in the clinical setting. They should also be aware that that same individual is likely to use unethical behaviors in the workplace and place client's health at risk.

Nursing administrators also have responsibilities in regard to the use of unethical behaviors in the workplace. They need to be aware that unethical behaviors are used in their institution and develop means of preventing use and dealing with individuals who use these behaviors. 
The novice nurse is at risk for using unethical behaviors. New graduates are often quickly placed in autonomous roles before they are ready for that challenge. Adequate guidance must be provided to novice nurses in decision making skills. Nonpunitive ways need to be developed to assist new nurses to deal with ethical concerns as they occur in the workplace.

One of the concerns in this study and others related to the reporting of medication errors. Gladstone (1995) suggested that institutions need to better define and recognize medication errors. Nurses need to recognize that reporting these errors decreases risks and damage to the client. The punitive aspects of error reporting need to be minimized. Perhaps these same principles can be applied to reporting of incidents and breaches of sterile technique.

A system of peer review may be helpful in eliminating use of unethical practice. A system of reporting peers' use of unethical behaviors needs to be developed. Some hospitals are also utilizing annual testing as a way of assessing nurses knowledge which may be useful in assisting nurses in updating their knowledge base.

There is no one easy remedy for eliminating the use of unethical behaviors. Recognition that these behaviors are used is the first step in developing actions plans in order to decrease the risk to client care. Implications for Research

First, this study should be repeated with a larger sample size. Additional demographic variables should be used to explore if they relate to the use of 
unethical behaviors. The sample used in this study consisted of registered nurses who were seeking either a bachelor's or master's degree. The study should be repeated with registered nurses who are not seeking further degrees to see if the two groups differ. Further study could examine cultural or religious influences on unethical behavior. Another variable, whether or not a participant has taken a course in ethics, should be examined. This may assist in determining ways to decrease use of unethical behaviors if an inverse relationship is found between use of unethical behaviors and completing a course in ethics.

Future studies should also examine what nurse educators, nurse administrators, student nurses and registered nurses define as unethical behaviors. These same groups may also be asked under what, if any, do they feel use of an unethical behavior may be justified.

This study only examined whether or not individuals used unethical behaviors during their initial nursing student experience and also in the workplace. Further studies should also examine the number of times each unethical behavior was used. Participants should also be asked to indicate their opinion of the severity of each unethical behavior. This would provide further insights into use of unethical behaviors. A qualitative study that examined the circumstances under which participants used unethical behaviors would provide further data related to use of unethical behaviors. A theoretical framework, such as Gilligan's (1982) could be used to analyze the data from a qualitative study. 
This study has demonstrated that individuals who use unethical behaviors in nursing school are more likely to use unethical behaviors in the workplace. Use of unethical behaviors has implications for the safety of clients in the health care system. Further studies in this area are imperative for the well being of all who will need health care. 


\section{References}

Aaron, R. M. (1992). Student academic dishonesty: Are collegiate institutions addressing the issue? NASPA Journal, 29 (2), 107-113.

Aaron, R. M. \& Georgia, R. T. (1994). Administrator perceptions of student academic dishonesty in collegiate institutions. NASPA Journal, 31 (2), 8391.

American Association of Colleges of Nursing. (1986). Essentials of College and University Education for Professioanl Nursing. Washington, DD: AACN American Nurses Association (1991). Standards of clinical nursing practice. Kansas City: ANA.

Bailey, P.A. (1990). Cheating among nursing students. Nurse Educator, 15 (3), $32-35$

Baird, J. S. (1980). Current trends in college cheating. Psychology in the Schools, 17, 515-522.

Baker, H. M. (1997). Rules outside the rules for administration of medication: A study in New South Wales, Australia. Image; Journal of Nursing Scholarship $29(2), 155-158$.

Barnett, D. C. \& Dalton, J. C. (1981). Why college students cheat. Journal of College Student Personnel, 22, 545-551.

Blacett, S. S. (1992). Plagiarism revisited. Nurse Educator, 17 (6), 4.

Board of Nursing (1994). Rules 59S. Jacksonville:Author.

Board of Nursing Newsletter. (1997). Jacksonville: Author 
Booth, D. E. \& Hoyer, P. J. (1992). Cheating: Faculty responsibilities when integrity fails. Nursing Outlook, 40 (2), 86-93.

Bradshaw, M. J. \& Lowenstein, A. J. (1990). Perspectives on academic dishonesty. Nurse Educator, 15 (5), 10-15.

Carmack, B. J. (1984). Exploring nursing educators' experience with student plagiarism. Nurse Educator, 9 (1), 29-33.

Chop, R. M. \& Silva, M. C. (1991). Scientific fraud: Definitions, policies, and implications for nursing research. Journal of Professional Nursing, 7 (3), $166-171$.

Clark, A. J. (1993). Responsible dissemination of scholarly work. Journal of Neuroscience Nursing, 25 (2), 113-7.

Daniel, L. G., Adams, B. N. ,\& Smith, N. M. (1994). Academic misconduct among nursing students: A multivariate investigation. Journal of Professional Nursing, 10 (5), 278-288.

Davis, S.F., Grover, C. A. , Becker, A. H., \& McGregor, L. N. (1992). Academic dishonesty: Prevalence, determinants, techniques, and punishments. Teaching of Psychology, 19 (1), 16-20.

Davis, M., Johnston, S.R., DiMarco, W., Findlay, M. P., \& Taylor, J.A. (1996). The case for a student honor code and beyond. Journal of Professional Nursing, 12 (1), 24-30.

Fosbinder, D. (1991). Cheating and plagiarism. Nurse Educator, 16 (6), 5. 
Fuqua, R. A. \& Stevens, K.R. (1988). What we know about medication errors: A literature review. Journal of Nursing Quality Assurance, 3 (1), 1-17.

Gilligan, Carol. (1982). In a Different Voice. Cambridge: Harvard University Press.

Gladstone, J. (1995). Drug administration errors: A study into the factors underlying the occurrence and reporting of drug errors in a district general hospital. Journal of Advanced Nursing, 22, 628-637.

Hackel, R., Butt, L. \& Banister, G. (1996). How nurses perceive medication errors. Nursing Management 27 (1), 31-34.

Haines, V. J., Diekhoff, G. M., LaBeff, E. E. \& Clark, R. E. (1986). COLLEGE CHEATING: Immaturity, lack of commitment and the neutralizing attitude. Research in Higher Education, 25 (4), 342-354.

Hansen, B. C. \& Hansen, K. D. (1995). Academic and scientific misconduct:

Issues for nursing educators. Journal of Professional Nursing. 11 (1), 31-39.

Harnest, P. (1986). The perceptions of student academic dishonesty by faculty and students in a school of nursing. Dissertation Abstracts International, 47 (08), 2825A. (University Microfilms International No. 8626025) Hawley, D. J. \& Jeffers, J. M. (1992). Scientific misconduct as a dilemma for nursing. IMAGE: Journal of Nursing Scholarship 24 (1), 51-55.

Hilbert, G .A. (1985). Involvement of nursing students in unethical classroom and clinical behaviors. Journal of Professional Nursing. 1 (4), 230-234. 
Hilbert, G. A. (1987). Academic fraud: prevalence, practices, and reasons. Journal of Professional Nursing. 4 (1), 39-45.

Hilbert, G .A. (1988). Moral development and unethical behaviors among nursing students. Journal of Professional Nursing, 4 (3), 163-167.

How ethical are you? (1983). NursingLife 3(1), 25-33.

Hoyer, P. J., Booth, D., Spelman, M.R. \& Richardson, C. E. (1991). Clinical cheating and moral development. Nursing Outlook, 39 (4), 170-173.

Jeffreys, M. R. \& Stier, L. A. (1991). Student academic dishonesty: Issues for nurse educators. DEAN'S Notes, 12 (3), 1-3.

Jefferys, M. R. \& Stier, L. A (1995). SPEAKING Against student academic dishonesty: A communication model for nurse educators. Journal of Nursing Education 34 (7), 297-304.

Jendrek, M. P. (1989). Faculty reactions to academic dishonesty. Journal of College Student Development, 30, 401-406.

Jendrek, M. P (1992). Student's reactions to academic dishonesty. Journal of College Student Development, 33, 260-273.

Jones, D. (1997, April 4-6). Doing the wrong thing. USA Today, p. 1A-2A. Karlins, M., Michales, C., Freilinger, P. \& Walker, H. (1989). Sex differences in academic dishonesty: College cheating in a management course. Journal of Education for Business, 65, 31-33.

Kelly, L. S. (1984). The pinnocchio principle. Nursing Outlook, 32 (6), 307. 
Kibler, W. L. (1994). Addressing academic dishonesty: What are institutions of higher education doing and not doing? NASPA Journal, 31 (20), 92-101.

LaBeff, E. E., Clark, R.E., Hines, V. J. \& Diekhoff, G. M. (1990). Situational ethics and college student cheating. Sociological Inquiry 60 (2), 190-198.

Ludeman, R. B. (1988). A survey of academic integrity practices in U. S. higher education. Journal of College Student Development, 29 (2), 172-173.

May, K. M. \& Loyd, B. H. (1993). Academic dishonesty: The honor system and students' attitudes. Journal of College Student Development, 34 (2), 125129.

McCabe, D. L. \& Bowers, D.L. (1994). Academic dishonesty among males in college: A thirty year perspective. Journal of College Student Development. $\underline{35}(1), 5-10$.

McCabe, D. L. \& Trevino, L. K. (1993). Academic dishonesty honor codes and other contextual influences. Journal of Higher Education, 64 (5), 522-538.

Millette, B. E. (1994). Using Gilligan's framework to analyze nurses' stories of moral choices. Western Journal of Nursing Research 16 (6), 660-674.

Nuss, E. (1984). Academic integrity: Comparing faculty and student attitudes. Improving College \& University Teaching. 32 (3), 140-144.

Pactor, H. S., McKeen, W. \& Morris, J. (1990). Students' ethics require new ways to cope with cheating. Educator, 44, 57-59.

Payne, S. L \& Nantz, K. S. (1994). Social accounts and metaphors about cheating. College Teaching 42 (3), 90-96. 
Peterson, L. B. (1986). "But we did it together;" or, Academic integrity and misrepresentation among college students. ERIC Document Reproduction Service No. HE 019799.

Prescott, P. A. (1989). Academic misconduct: Consideration for educational administrators. Journal of Professional Nursing, 5 (5), 283-287.

Pratt, C. B. \& McLaughlin, G.W. (1989). An analysis of predictors of college students' ethical inclinations. Research in Higher Education, 30 (2), 195219.

Raffetto, W. G. (1985). The cheat. Community and Junior College Journal, 56 (2), 27.

Rogers, P. (1997, January 24). Unreported medical errors 'a time bomb.' Miami Herald, p. B1.

Roth, N. L. \& McCabe, D. L. (1995). Communication strategies for addressing academic dishonesty. Journal of College Student Development, 36 (6), 531 540.

Saunders, E. J. (1993). Confronting academic dishonesty. Journal of Social Work Education, 29 (2), 24-231.

Schmitz, K. \& Schaffer, M. (1995). Ethical problems encountered in the teaching of nursing; Student and faculty perceptions. Journal of Nursing Education, $\underline{34}(1), 42-44$.

Seirles, F., Hendrickx, I. \& Circle, S. (1980). Cheating in medical school. The Jouranl of Medical Education, 55, 124-125. 
Sheer, B. L. (1989). The relationship among socialization, empathy, autonomy, and unethical behaviors in baccalaureate nursing students. Dissertation Abstracts International 51 (01), 0147B .

Sims, R. (1995). The severity of academic dishonesty: A comparison of faculty and student views. Psychology in the Schools, 32 (3), 233-238.

Sims, R. (1993). The relationship between academic dishonesty and unethical business practices. Journal of Education for Business, 68 (4), 207-11.

Stevens, G. E. \& Stevens, F. W. (1987). Ethical inclinations of tomorrow's managers revisited: How and why students cheat. Journal of Education for Business, 63, 24-29.

Stern, E. B. \& Havlicek, L. (1986). Academic misconduct: Results of faculty and undergraduate student surveys. Journal of Allied Health, 15 (2), 129-143.

Sutton, E. M. \& Huba, M. E. (1995). Undergraduate student perceptions of academic dishonesty as a function of ethnicity and religious participation. NASPA Journal, 33 (1), 19-34.

Sykes, G. \& Matza, D. (1957). Techniques of neutralization: A theory of delinquency. American Sociological Review, 22, 664-670.

Tauber, R. T (1984). Cheating and plagiarism: Matters beyond a faculty member's right to decide. New Orleans: Paper presented at the Annual Meeting of the National Association of Teacher Educators.. (ERIC Document Reproduction Service No. HE 107 082). 
Taylor, C., Lillis, C. \& LeMone, P. (1997). Fundamentals of nursing: The art and science of nursing care. Philadelphia: J.B.Lippincott Company.

Theis, E. C. (1988). Nursing student's perspectives of unethical teaching behaviors. Journal of Nursing Education, 27 (3), 102-106.

Todd-Mancillas, W.R. et al. (1987). Academic dishonesty among communication students and professionals: Some consequences and what might be done about them. Paper presented at the annual meeting of the Speech Communication Association, Boston. (ERIC Document Reproduction Center No. ED 296 406)

Tom, G. \& Borin, N. (1988). Cheating in academe. Journal of Education for Business, 63 (3), 153-157.

Wolf, Z. R., Haakenson, D. A., Seeger Jablonski, R. A S. \& McGoldrick, T. B. (1995). Nurses' perceptions of harmful outcomes from medication errors. MEDSURG Nursing, 4 (6), 460-467. 
Appendix A

Self Report of Unethical Behaviors Inventory

Dear Participant,

Your participation in this research project is being requested. The researcher in this study is Lynne Bryant, a student in the College of Education at Florida International University. The study will examine self-reported behaviors of nursing students and registered nurses.

In this study, you will be asked to complete one questionnaire which should take about 20 minutes to finish.

Participation in this study is voluntary. There is no penalty if you choose not to participate.

The information you provide is anonymous. No individual results will be reported in this study. All answers from the questionnaire will be published as group data, so you will not be identified in any way. Data will be kept locked in the researcher's files.

Your completion of the survey is your consent to participate. If you do not wish to participate, you might want to read over the survey and think about how you would respond to the questions. Once you complete the questionnaire, your participation cannot be withdrawn since no individual is identifiable.

If you have questions about this study, you may contact me at (954) 4756774 or my supervisor, Dr. Janice Sandiford at (305) 919-5832.

Before completing this questionnaire, please remove this cover letter and keep it for your records.

Thank you for participating in this study.

Sincerely,

Lynne Bryant, RN, MSN

Note: continued on next page 


\section{Directions}

Many people view different behaviors in different ways. In this survey, you will be asked to indicate which behaviors you may have engaged in different settings.

Do not write your name on this questionnaire. Any information reported on this questionnaire will remain anonymous.

Please place a check in the appropriate space.

Initial nursing education to become a registered nurse.
ADN
Diploma
BSN
Other (specify)

Please indicate in the space provided the approximate number of years you have actively practiced as a registered nurse.

years of practice

Where did you spend the majority of time between birth and age $18 ?$ in the U.S. outside the U.S. about $50 \%$ in the U.S. and $50 \%$ outside the U.S.

Thank you for your assistance.

Note: continued on next page 


\section{Section A}

Please circle $Y$ next to any statement which describes your behavior as a student during your initial nursing education to become a registered nurse. Circle $\mathbf{N}$ next to any statement which does not describe your behavior as a student in your initial nursing education to become a registered nurse.

\section{As a student I once (or more):}

\begin{tabular}{|c|c|c|c|}
\hline $\mathbf{Y}$ & $\mathbf{N}$ & 1. & copied an answer from another student's examination or quiz. \\
\hline $\mathbf{Y}$ & $\mathbf{N}$ & 2. & allowed another student to copy from my examination or test paper. \\
\hline Y & $\mathrm{N}$ & 3. & used notes during an examination or quiz when it was not permitted. \\
\hline $\mathbf{Y}$ & $\mathrm{N}$ & 4. & took a test for another student. \\
\hline Y & $\mathbf{N}$ & 5. & $\begin{array}{l}\text { copied a few sentences from a reference without giving credit to the } \\
\text { reference. }\end{array}$ \\
\hline Y & $\mathbf{N}$ & 6. & used references for a paper that were not listed in the bibliography. \\
\hline $\mathbf{Y}$ & $\mathbf{N}$ & 7. & turned in an assignment as my own when it was done by someone else. \\
\hline Y & $\mathrm{N}$ & 8. & $\begin{array}{l}\text { worked with another student on an assignment when the instructor did } \\
\text { not permit it. }\end{array}$ \\
\hline $\mathbf{Y}$ & $\mathbf{N}$ & 9. & asked another student to take an examination for me. \\
\hline$Y$ & $\mathbf{N}$ & 10. & prepared an assignment for another student to submit as their own work. \\
\hline $\mathbf{Y}$ & $\mathbf{N}$ & 11. & gave a false reason for being absent from clinical or class \\
\hline Y & $\mathrm{N}$ & 12. & went to the clinical area under the influence of alcohol or drugs. \\
\hline Y & $\mathbf{N}$ & 13. & took equipment from the hospital for personal use. \\
\hline $\mathbf{Y}$ & $\mathbf{N}$ & 14. & took medications from the hospital for personal use. \\
\hline $\mathbf{Y}$ & $\mathrm{N}$ & 15. & recorded medications as given even though they were not given. \\
\hline Y & $\mathbf{N}$ & 16. & $\begin{array}{l}\text { recorded that treatments or observations as completed when they had } \\
\text { not been done }\end{array}$ \\
\hline $\mathbf{Y}$ & $\mathbf{N}$ & 17. & talked about patients in public areas of the hospital. \\
\hline
\end{tabular}

Note: continued on next page 


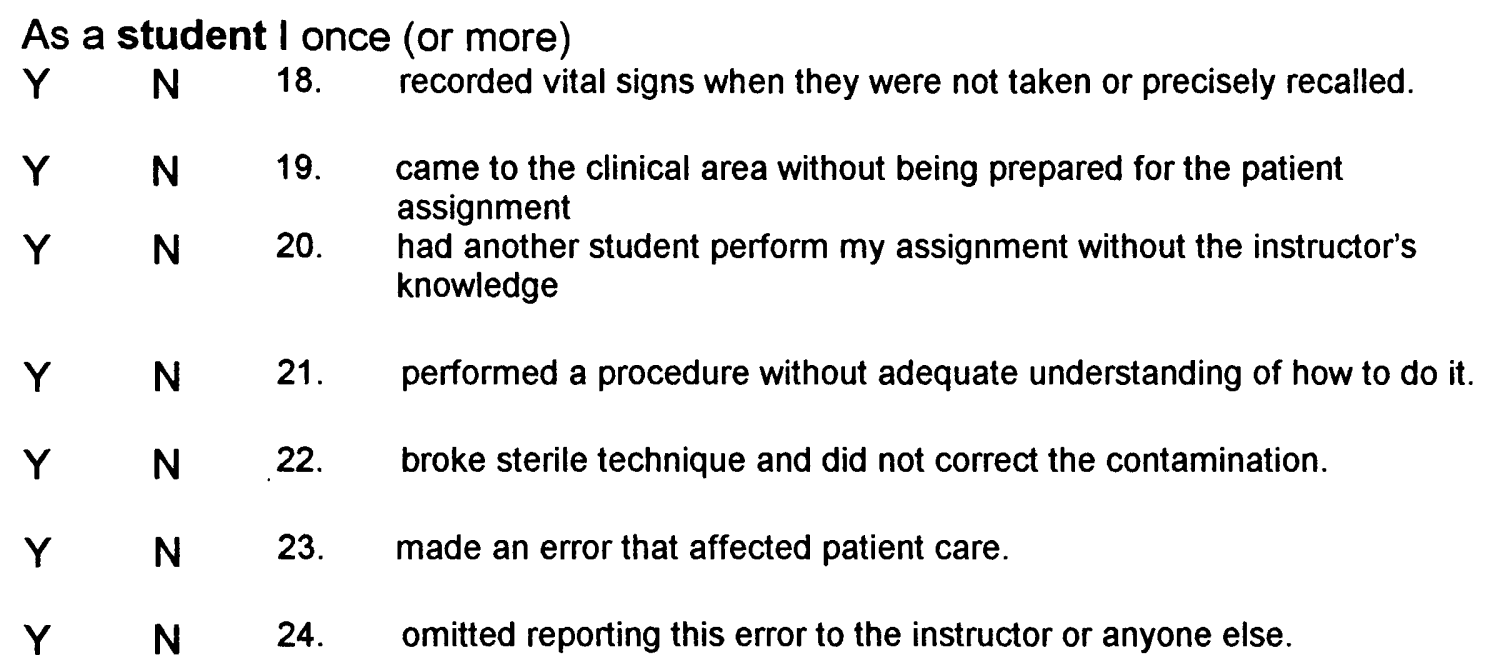

\section{Section B}

Please circle $\mathrm{Y}$ next to any statement which describes your behavior as a registered nurse. Circle $\mathrm{N}$ next to any statement which does not describe your behavior as a registered nurse.

In my nursing practice I once (or more):

$\mathrm{Y} \quad \mathrm{N} \quad 25$. photocopied personal papers.

Y N 26. took credit for someone else's ideas or work.

Y N 27. gave a false reason for being absent from work.

Y N 28. went to the work under the influence of alcohol or drugs.

$\begin{array}{lll}\mathrm{N} & \mathrm{N} & 29 . \\ \text { took hospital equipment for personal use. }\end{array}$

Y $\quad \mathrm{N} 30$. took medications from the hospital for personal use.

$\mathrm{Y} \quad \mathrm{N} \quad 31$ recorded medications as given even though they were not given.

$\mathrm{Y} \quad \mathrm{N}$ 32. recorded that treatments or observations as completed when they had not been done.

Y N 33. talked about patients in public areas of the hospital

Y N 34. recorded vital signs when they were not taken or precisely recalled.

Note: continued on next page 
In my nursing practice I once (or more):

$\mathrm{Y} \quad \mathrm{N} \quad 35$. performed a procedure without adequate understanding of how to do it

Y N 36. broke sterile technique and did not correct the contamination.

$\mathrm{Y} \quad \mathrm{N}$ 37. made a medication error.

$\mathrm{Y} \quad \mathrm{N} \quad 38$. omitted reporting the medication error.

Y $\quad \mathrm{N}$ 39. was involved in an incident related to a patient or visitor.

$\mathrm{Y} \quad \mathrm{N}$ 40. omitted reporting the incident involving a patient or visitor.

\section{Section C}

Please circle $Y$ next to any statement which describes behavior that you are aware of another registered nurse doing. Circle $\mathrm{N}$ next to any statement which you are not aware of another registered nurse doing.

I know of a nurse who:

Y N $\quad \mathrm{N}$. photocopied personal papers.

Y N 42. took credit for someone else's ideas or work.

$\mathrm{Y} \quad \mathrm{N}$ 43. gave a false reason for being absent from work.

$\mathrm{Y} \quad \mathrm{N}$ 44. came to work under the influence of alcohol or drugs.

Y N 45. took hospital equipment for personal use.

Y N 46. took medications from the hospital for personal use.

$\mathrm{Y} \quad \mathrm{N} \quad 47$. recorded medications as given even though they were not given.

$\mathrm{Y} \quad \mathrm{N} \quad 48$ recorded that treatments or observations as completed when they had not been done.

$\mathrm{Y} \quad \mathrm{N}$ 49. talked about patients in public areas of the hospital

Y N 50. recorded vital signs when they were not taken or precisely recalled.

$\mathrm{Y} \quad \mathrm{N} 51$ performed a procedure without adequate understanding of how to do it

Note: continued on next page 


\section{Appendix A (con't)}

I know of a nurse who:

$\mathrm{Y} \quad \mathrm{N} 52$ broke sterile technique and did not correct the contamination.

$\mathrm{Y} \quad \mathrm{N} \quad$ 53. made a medication error.

$\mathrm{Y} \quad \mathrm{N} \quad 54$ omitted reporting the medication error.

Y N 55. was involved in an incident related to a patient or visitor.

Y N 56. omitted reporting the incident involving a patient or visitor. 
Faculty Cover Letter and Rating Form

Dear Colleague:

I am currently conducting a research study that examines the relationship between participation in unethical behaviors by nursing students and their participation in unethical behaviors as registered nurses. A second part of this study relates to the severity of these unethical behaviors in which nursing students and nurses may participate. The relationship between the severity of behaviors engaged in as nursing students and the severity of those engaged in as registered nurses will be studied.

Would you be willing to participate in this study as a nurse educator expert? Please rate the following list behaviors according to what you believe is the severity of unethical behavior if engaged in by a nursing student. It should take less than ten minutes to complete the attached pages. Please return them to your co-worker who gave them to you. You will need you to give your name, degrees and title to your co-worker so that I will have data available regarding the experts who are participating in this study.

Thank you for assisiting me with this study. Once the study is completed I will send you an abstract of the study.

Sincerely,

Lynne Bryant, MSN, RN

Note: continued on next page 
Please rate each of the following behaviors according to what you believe to be the severity of unethical behavior if engaged in by nursing students in their initial nursing educational experience.

1. copying an answer from another student's examination or quiz.

$\begin{array}{clccc}1 & 2 & 3 & 4 & 5 \\ \text { not } & \text { slightly } & \text { somewhat } & \text { moderately } & \begin{array}{c}\text { severely } \\ \text { unethical }\end{array} \\ \text { unethical } & \text { unethical } & \text { unethical } & \text { unethical }\end{array}$

2. allowing another student to copy from an examination or test paper.

$\begin{array}{clccc}1 & 2 & 3 & 4 & 5 \\ \text { not } & \text { slightly } & \text { somewhat } & \text { moderately } & \text { severely } \\ \text { unethical } & \text { unethical } & \text { unethical } & \text { unethical } & \text { unethical }\end{array}$

3. using notes during an examination or quiz when it was not permitted.

$\begin{array}{clccc}1 & 2 & 3 & 4 & 5 \\ \text { not } & \text { slightly } & \text { somewhat } & \begin{array}{c}\text { moderately } \\ \text { unethical }\end{array} & \begin{array}{c}\text { severely } \\ \text { unethical }\end{array} \\ \text { unethical } & \text { unethical } & \text { uneal }\end{array}$

4. taking a test for another student.

$\begin{array}{cllcc}1 & 2 & 3 & 4 & 5 \\ \text { not } & \text { slightly } & \text { somewhat } & \text { moderately } & \begin{array}{c}\text { severely } \\ \text { unethical }\end{array} \\ \text { unethical } & \text { unethical } & \text { unethical } & \text { unethical } & \text { unet }\end{array}$

5. copying a few sentences from a reference without giving credit to the reference.

$\begin{array}{ccccc}1 & 2 & 3 & 4 & 5 \\ \text { not } & \text { slightly } & \text { somewhat } & \text { moderately } & \text { severely } \\ \text { unethical } & \text { unethical } & \text { unethical } & \text { unethical } & \text { unethical }\end{array}$

6. using references for a paper that were not listed in the bibliography.

$\begin{array}{ccccc}1 & 2 & 3 & 4 & 5 \\ \text { not } & \text { slightly } & \text { somewhat } & \text { moderately } & \begin{array}{c}\text { severely } \\ \text { unethical }\end{array} \\ \text { unethical } & \text { unethical } & \text { unethical } & \text { unethical } & \text { unethical }\end{array}$

7. turning in an assignment as their own when it was done by someone else.

$\begin{array}{clccc}1 & 2 & 3 & 4 & 5 \\ \text { not } & \text { slightly } & \text { somewhat } & \text { moderately } & \text { severely } \\ \text { unethical } & \text { unethical } & \text { unethical } & \text { unethical } & \text { unethical }\end{array}$

Note: continued on next page 
Appendix B (con't)

8. working with another student on an assignment when the instructor did not permit it.

$\begin{array}{clccc}1 & 2 & 3 & 4 & 5 \\ \text { not } & \text { slightly } & \text { somewhat } & \begin{array}{c}\text { moderately } \\ \text { unethical }\end{array} & \begin{array}{c}\text { severely } \\ \text { unethical }\end{array} \\ \text { unethical } & \text { unethical } & \text { unethical }\end{array}$

9. asking another student to take an examination for them.

$\begin{array}{clccc}1 & 2 & 3 & 4 & 5 \\ \text { not } & \text { slightly } & \text { somewhat } & \text { moderately } & \text { severely } \\ \text { unethical } & \text { unethical } & \text { unethical } & \text { unethical } & \text { unethical }\end{array}$

10. preparing an assignment for another student to submit as their own work.

$\begin{array}{clccc}1 & 2 & 3 & 4 & 5 \\ \text { not } & \text { slightly } & \text { somewhat } & \begin{array}{c}\text { moderately } \\ \text { unethical }\end{array} & \begin{array}{c}\text { severely } \\ \text { unethical }\end{array}\end{array}$

11. giving a false reason for being absent from clinical or class

$\begin{array}{clccc}1 & 2 & 3 & 4 & 5 \\ \text { not } & \text { slightly } & \text { somewhat } & \text { moderately } & \text { severely } \\ \text { unethical } & \text { unethical } & \text { unethical } & \text { unethical } & \text { unethical }\end{array}$

12. coming to the clinical area under the influence of alcohol or drugs.

\begin{tabular}{|c|c|c|c|c|}
\hline $\begin{array}{c}1 \\
\text { not } \\
\text { unethical }\end{array}$ & $\begin{array}{l}\quad 2 \\
\text { slightly } \\
\text { unethical }\end{array}$ & $\begin{array}{c}3 \\
\text { somewhat } \\
\text { unethical }\end{array}$ & \begin{tabular}{l}
\multicolumn{1}{c}{4} \\
moderately \\
unethical
\end{tabular} & $\begin{array}{l}5 \\
\text { severely } \\
\text { unethical }\end{array}$ \\
\hline
\end{tabular}

13. taking equipment from the hospital for personal use.

$\begin{array}{ccccc}1 & 2 & 3 & 4 & 5 \\ \text { not } & \text { slightly } & \text { somewhat } & \text { moderately } & \begin{array}{c}\text { severely } \\ \text { unethical }\end{array} \\ \text { unethical } & \text { unethical } & \text { unethical } & \text { unethical }\end{array}$

14. taking medications from the hospital for personal use.

$\begin{array}{ccccc}1 & 2 & 3 & 4 & 5 \\ \text { not } & \text { slightly } & \text { somewhat } & \text { moderately } & \text { severely } \\ \text { unethical } & \text { unethical } & \text { unethical } & \text { unethical } & \text { unethical }\end{array}$

Note: continued on next page 
Apendix B (con't)

15. recording medications as given even though they were not given.

\begin{tabular}{|c|c|c|c|}
\hline $\begin{array}{c}1 \\
\text { not } \\
\text { unethical }\end{array}$ & $\begin{array}{l}2 \\
\text { slightly } \\
\text { unethical }\end{array}$ & $\begin{array}{c}3 \\
\text { somewhat } \\
\text { unethical }\end{array}$ & $\begin{array}{l}\quad 4 \\
\text { moderately } \\
\text { unethical }\end{array}$ \\
\hline
\end{tabular}

16. recording that treatments or observations as completed when they had not been done

\begin{tabular}{|c|c|c|c|}
\hline $\begin{array}{c}1 \\
\text { not } \\
\text { unethical }\end{array}$ & $\begin{array}{c}2 \\
\text { slightly } \\
\text { unethical }\end{array}$ & $\begin{array}{c}3 \\
\text { somewhat } \\
\text { unethical }\end{array}$ & \begin{tabular}{l}
\multicolumn{1}{c}{4} \\
moderately \\
unethical
\end{tabular} \\
\hline
\end{tabular}

17. talking about patients in public areas of the hospital.

\begin{tabular}{|c|c|c|c|}
\hline $\begin{array}{c}1 \\
\text { not } \\
\text { unethical }\end{array}$ & $\begin{array}{l}2 \\
\text { slightly } \\
\text { unethical }\end{array}$ & $\begin{array}{c}3 \\
\text { somewhat } \\
\text { unethical }\end{array}$ & \begin{tabular}{l}
\multicolumn{1}{c}{} \\
moderately \\
unethical
\end{tabular} \\
\hline
\end{tabular}

18. recording vital signs when they were not taken or precisely recalled.

$\begin{array}{cllll}1 & 2 & 3 & 4 & 5 \\ \text { not } & \text { slightly } & \text { somewhat } & \text { moderately } & \text { severely } \\ \text { unethical } & \text { unethical } & \text { unethical } & \text { unethical } & \text { unethical }\end{array}$

19. coming to the clinical area without being prepared for the patient assignment

$\begin{array}{clccc}1 & 2 & 3 & 4 & 5 \\ \text { not } & \text { slightly } & \text { somewhat } & \text { moderately } & \text { severely } \\ \text { unethical } & \text { unethical } & \text { unethical } & \text { unethical } & \text { unethical }\end{array}$

20. having another student perform an assignment without the instructor's knowledge

\begin{tabular}{|c|c|c|c|c|}
\hline $\begin{array}{c}1 \\
\text { not } \\
\text { unethical }\end{array}$ & $\begin{array}{l}2 \\
\text { slightly } \\
\text { unethical }\end{array}$ & $\begin{array}{c}3 \\
\text { somewhat } \\
\text { unethical }\end{array}$ & $\begin{array}{l}\quad 4 \\
\text { moderately } \\
\text { unethical }\end{array}$ & $\begin{array}{l}5 \\
\text { severely } \\
\text { unethical }\end{array}$ \\
\hline
\end{tabular}

21. performing a procedure without adequate understanding of how to do it.

$\begin{array}{clccc}1 & 2 & 3 & 4 & 5 \\ \text { not } & \text { slightly } & \text { somewhat } & \begin{array}{c}\text { moderately } \\ \text { unethical }\end{array} & \begin{array}{c}\text { severely } \\ \text { unethical }\end{array} \\ \text { unethical } & \text { unethical } & \text { uneal }\end{array}$

Note: continued on next page 
Appendix B (con't)

22. breaking sterile technique and not correcting the contamination.

\begin{tabular}{|c|c|c|c|}
\hline $\begin{array}{c}1 \\
\text { not } \\
\text { unethical }\end{array}$ & $\begin{array}{l}2 \\
\text { slightly } \\
\text { unethical }\end{array}$ & $\begin{array}{c}3 \\
\text { somewhat } \\
\text { unethical }\end{array}$ & $\begin{array}{l}\quad 4 \\
\text { moderately } \\
\text { unethical }\end{array}$ \\
\hline
\end{tabular}

23. making an error that affected patient care.

\begin{tabular}{|c|c|c|c|}
\hline $\begin{array}{c}1 \\
\text { not } \\
\text { unethical }\end{array}$ & $\begin{array}{c}2 \\
\text { slightly } \\
\text { unethical }\end{array}$ & $\begin{array}{c}3 \\
\text { somewhat } \\
\text { unethical }\end{array}$ & $\begin{array}{l}\quad 4 \\
\text { moderately } \\
\text { unethical }\end{array}$ \\
\hline
\end{tabular}

24. omitting reporting this error to the instructor or anyone else.

$\begin{array}{clccc}1 & 2 & 3 & 4 & 5 \\ \text { not } & \text { slightly } & \text { somewhat } & \text { moderately } & \text { severely } \\ \text { unethical } & \text { unethical } & \text { unethical } & \text { unethical } & \text { unethical }\end{array}$


Dear Colleague:

I am currently conducting a research study that examines the relationship between participation in unethical behaviors by nursing students and their participation in unethical behaviors as registered nurses. A second part of this study relates to the severity of these unethical behaviors in which nursing students and nurses may participate. The relationship between the severity of behaviors engaged in as nursing students and the severity of those engaged in as registered nurses will be studied.

Would you be willing to participate in this study as an expert? Please rate the following list of behaviors according to what you believe is the severity of unethical behavior if engaged in by a registered nurse. It should take less than ten minutes to complete the attached pages. Please return them to your co worker. You will need to give your name, degrees and title to her so that I will have that data available regarding the experts who are participating in this study.

Thank you for assisting me in this study. Once the study is completed I will send you an abstract of the study.

Sincerely,

Lynne Bryant, MSN, RN

Note: continued on next page 


\section{Appendix C (con't)}

Please rate each of the following behaviors according to what you believe to be the severity of the unethical behavior if engaged in by a registered nurse.

1. photocopying personal papers at work.

$\begin{array}{cllcc}1 & 2 & 3 & 4 & 5 \\ \text { not } & \text { slightly } & \text { somewhat } & \text { moderately } & \begin{array}{c}\text { severely } \\ \text { unethical }\end{array} \\ \text { unethical } & \text { unethical } & \text { unethical } & \text { unethical }\end{array}$

2. taking credit for someone else's ideas or work.

\begin{tabular}{|c|c|c|c|}
\hline $\begin{array}{c}1 \\
\text { not } \\
\text { unethical }\end{array}$ & $\begin{array}{l}2 \\
\text { slightly } \\
\text { unethical }\end{array}$ & $\begin{array}{l}3 \\
\text { somewhat } \\
\text { unethical }\end{array}$ & $\begin{array}{c}4 \\
\text { moderately } \\
\text { unethical }\end{array}$ \\
\hline
\end{tabular}

3. giving a false reason for being absent from work.

$\begin{array}{clccc}1 & 2 & 3 & 4 & 5 \\ \text { not } & \text { slightly } & \text { somewhat } & \text { moderately } & \begin{array}{c}\text { severely } \\ \text { unethical }\end{array} \\ \text { unethical } & \text { unethical } & \text { unethical } & \text { unethical } & \text { unet }\end{array}$

4. coming to the work under the influence of alcohol or drugs.

$\begin{array}{clccc}1 & 2 & 3 & 4 & 5 \\ \text { not } & \text { slightly } & \text { somewhat } & \text { moderately } & \begin{array}{c}\text { severely } \\ \text { unethical }\end{array} \\ \text { unethical } & \text { unethical } & \text { unethical } & \text { unethical } & \text { unet }\end{array}$

5. taking hospital equipment for personal use.

$\begin{array}{clccc}1 & 2 & 3 & 4 & 5 \\ \text { not } & \text { slightly } & \text { somewhat } & \text { moderately } & \begin{array}{c}\text { severely } \\ \text { unethical }\end{array} \\ \text { unethical } & \text { unethical } & \text { unethical } & \text { unethical } & \text { unethical }\end{array}$

6. taking medications from the hospital for personal use.

\begin{tabular}{|c|c|c|c|c|}
\hline $\begin{array}{c}1 \\
\text { not } \\
\text { Inethical }\end{array}$ & $\begin{array}{l}2 \\
\text { slightly } \\
\text { unethical }\end{array}$ & $\begin{array}{l}3 \\
\text { somewhat } \\
\text { unethical }\end{array}$ & $\begin{array}{l}\quad 4 \\
\text { moderately } \\
\text { unethical }\end{array}$ & $\begin{array}{c}5 \\
\text { severely } \\
\text { unethical }\end{array}$ \\
\hline
\end{tabular}

7. recording medications as given even though they were not given.

\begin{tabular}{|c|c|c|c|c|}
\hline $\begin{array}{c}1 \\
\text { not } \\
\text { unethical }\end{array}$ & $\begin{array}{l}2 \\
\text { slightly } \\
\text { unethical }\end{array}$ & $\begin{array}{c}3 \\
\text { somewhat } \\
\text { unethical }\end{array}$ & $\begin{array}{l}4 \\
\text { moderately } \\
\text { unethical }\end{array}$ & $\begin{array}{l}5 \\
\text { severely } \\
\text { unethical }\end{array}$ \\
\hline
\end{tabular}

Note: continued on next page 


\section{Appendix C (con't)}

8. recording that treatments or observations were completed when they had not been done.

$\begin{array}{clccc}1 & 2 & 3 & 4 & 5 \\ \text { not } & \text { slightly } & \text { somewhat } & \begin{array}{c}4 \\ \text { moderately }\end{array} & \begin{array}{c}\text { severely } \\ \text { unethical }\end{array} \\ \text { unethical } & \text { unethical } & \text { unethical } & \text { unethical } & \text { unet }\end{array}$

9. talking about patients in public areas of the hospital

$\begin{array}{cllcc}1 & 2 & 3 & 4 & 5 \\ \text { not } & \text { slightly } & \text { somewhat } & \text { moderately } & \text { severely } \\ \text { unethical } & \text { unethical } & \text { unethical } & \text { unethical } & \text { unethical }\end{array}$

10. recording vital signs when they were not taken or precisely recalled.

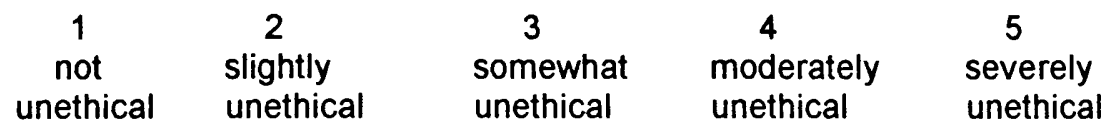

11. performing a procedure without adequate understanding of how to do it

\begin{tabular}{|c|c|c|c|c|}
\hline $\begin{array}{c}1 \\
\text { not } \\
\text { unethical }\end{array}$ & $\begin{array}{l}2 \\
\text { slightly } \\
\text { unethical }\end{array}$ & $\begin{array}{c}3 \\
\text { somewhat } \\
\text { unethical }\end{array}$ & $\begin{array}{c}4 \\
\text { moderately } \\
\text { unethical }\end{array}$ & $\begin{array}{c}5 \\
\text { severely } \\
\text { unethical }\end{array}$ \\
\hline
\end{tabular}

12. breaking sterile technique and not correcting the contamination.

$\begin{array}{clccc}1 & 2 & 3 & 4 & 5 \\ \text { not } & \text { slightly } & \text { somewhat } & \text { moderately } & \text { severely } \\ \text { unethical } & \text { unethical } & \text { unethical } & \text { unethical } & \text { unethical }\end{array}$

13. making a medication error.

$\begin{array}{ccccc}1 & 2 & 3 & 4 & 5 \\ \text { not } & \text { slightly } & \text { somewhat } & \text { moderately } & \begin{array}{c}\text { severely } \\ \text { unethical }\end{array} \\ \text { unethical } & \text { unethical } & \text { unethical } & \text { unethical } & \text { unet }\end{array}$

14. omitting reporting a medication error.

$\begin{array}{clccc}1 & 2 & 3 & 4 & 5 \\ \text { not } & \text { slightly } & \text { somewhat } & \text { moderately } & \begin{array}{c}\text { severely } \\ \text { unethical }\end{array} \\ \text { unethical } & \text { unethical } & \text { unethical } & \text { unethical } & \text { une }\end{array}$

Note: continued on next page 


\section{Appendix C (con't)}

15. being involved in an incident related to a patient or visitor.

\begin{tabular}{|c|c|c|c|c|}
\hline $\begin{array}{c}1 \\
\text { not } \\
\text { unethical }\end{array}$ & $\begin{array}{l}2 \\
\text { slightly } \\
\text { unethical }\end{array}$ & $\begin{array}{l}3 \\
\text { somewhat } \\
\text { unethical }\end{array}$ & $\begin{array}{c}4 \\
\text { moderately } \\
\text { unethical }\end{array}$ & $\begin{array}{c}5 \\
\text { severely } \\
\text { unethical }\end{array}$ \\
\hline
\end{tabular}

16. omitting reporting an incident involving a patient or visitor.

$\begin{array}{clccc}1 & 2 & 3 & 4 & 5 \\ \text { not } & \text { slightly } & \text { somewhat } & \text { moderately } & \begin{array}{c}\text { severely } \\ \text { unethical }\end{array}\end{array}$


1970

1970-1976

1976

1977-1979

1979

1979-1982

1982-1986

1988-1992

1993-1997

1989-present
Diploma in Nursing Johns Hopkins Hospital

Baltimore, Maryland

Medical-Surgical Nurse Baltimore, Maryland and Washington, D.C.

B.S.N., Nursing

University of Maryland

Baltimore, Maryland

Nurse Administrator

Washington, D.C. and

Philadelphia, Pennsylvania

M.S.N., Nursing

University of Pennsylvania

Philadelphia, Pennsylvania

Instructor

Methodist Hospital

Philadelphia, Pennsylvania

Nurse Administrator

Marlton, New Jersey

Critical Care Nurse

Philadelphia, Pennsylvania and

Ft. Lauderdale, Florida

Doctorate in Education

Florida International University

Miami, Florida

Instructor

Broward Community College

Davie, Florida 
